\title{
Radiation Synthesis and Characterization of Poly(Vinyl Alcohol)/ Acrylamide/ TiO2/ SiO2 Nanocomposite for Removal of Metal Ion and Dye From Waste Water
}

\section{Ahmed Elbarbary ( $\nabla$ amelbarbary@yahoo.com )}

Radiation Research of Polymer Chemistry Department, National Center for Radiation Research and Technology, Egyptian Atomic Energy Authority, Cairo, Egypt https://orcid.org/0000-0001-5318-602X Yasser H. Gad

Radiation Research of Polymer Chemistry Department, National Center for Radiation Research and Technology, Egyptian Atomic Energy Authority, Cairo, Egypt

\section{Research Article}

Keywords: radiation polymerization, poly(vinyl alcohol), acrylamide, $\mathrm{TiO} 2, \mathrm{SiO} 2$, nanocomposite, basic blue 3 dye, copper ions. adsorption, removal

Posted Date: March 24th, 2021

DOl: https://doi.org/10.21203/rs.3.rs-346264/v1

License: (9) This work is licensed under a Creative Commons Attribution 4.0 International License. Read Full License 


\title{
Radiation synthesis and characterization of poly(vinyl alcohol)/ acrylamide/ $\mathrm{TiO}_{2} /$ $\mathrm{SiO}_{2}$ nanocomposite for removal of metal ion and dye from waste water
}

\author{
Ahmed M. Elbarbary* and Yasser H. Gad \\ Radiation Research of Polymer Chemistry Department, National Center for Radiation \\ Research and Technology, Egyptian Atomic Energy Authority, Cairo, Egypt
}

\begin{abstract}
An effective and novel adsorbent of poly(vinyl alcohol)/polyacrylamide $/ \mathrm{TiO}_{2} / \mathrm{SiO}_{2}$ (PVA-co-AAm/ $/ \mathrm{TiO}_{2} / \mathrm{SiO}_{2}$ ) nanocomposite synthesized by $\gamma$-irradiation polymerization of PVA and AAm in presence of $\mathrm{TiO}_{2} / \mathrm{SiO}_{2}$ nanoparticles at different irradiation doses $(10,30$ and $50 \mathrm{kGy}$ ) for removal of $\mathrm{Cu}(\mathrm{II})$ ions and basic blue 3 dye from their aqueous solutions. FT-IR, TEM, XRD, SEM, EDS and DLS analyzed the chemical properties of nanocomposites. The nanocomposite prepared at $30 \mathrm{kGy}$ (PVA-co-AAm/ $/ \mathrm{TiO}_{2} / \mathrm{SiO}_{2}-30$ ) shows high swelling of $197.7(\%)$ and gelation of $93.1 \%$. The adsorption capacity $(\mathrm{mg} / \mathrm{g})$ and removal (\%) of basic blue 3 dye and $\mathrm{Cu}(\mathrm{II})$ ions onto nanocomposites by varying experimental conditions were investigated. The PVA-co-AAm/ $/ \mathrm{TiO}_{2} / \mathrm{SiO}_{2}-30$ showed high adsorption capacity 3 folds rather than PVA-co-AAm. The equilibrium adsorption for basic blue 3 dye and $\mathrm{Cu}(\mathrm{II})$ was $123.9 \mathrm{mg} / \mathrm{g}$ and $190.3 \mathrm{mg} / \mathrm{g}$ with removal of 82.6 and $95.1 \%$, respectively. The results of the adsorption of dye or metal ions follow the Pseudo-second order adsorption kinetic, fit with the Langmuir isotherm and the adsorption process is endothermic and spontaneous in nature. The results revealed that the PVA-co$\mathrm{AAm} / \mathrm{TiO}_{2} / \mathrm{SiO}_{2}$ nanocomposites could be employed as an effectual adsorbent for adsorption of basic blue dye and $\mathrm{Cu}(\mathrm{II})$ ions from wastewater with high adsorption capacity and recovery.
\end{abstract}

Keywords: radiation polymerization; poly(vinyl alcohol), acrylamide; $\mathrm{TiO}_{2} ; \mathrm{SiO}_{2}$, nanocomposite; basic blue 3 dye; copper ions; adsorption; removal

Corresponding author: Ahmed M. Elbarbary

E.mail:amelbarbary@yahoo.com, ahmed.elbarbary@eaea.org.eg

\section{Introduction}

Industrial wastewater are regularly contaminated with an assortment of compounds that give a negative effects on the environment. ${ }^{1}$ A great amount of heavy metals for example $\mathrm{Cu}$ (II) ions released in wastewater by industries wastes. ${ }^{2}$ One of the difficulties correlated with the occurrence of heavy metals in wastewater is that they are not biodegradable in an aquatic media, and so they can be consumed by organisms, and consequently, go into the food chain. Human body contains copper, and it plays a significant function for the development of bones and tissues or in enzyme creation. ${ }^{3}$ On the other hand, an overload of $\mathrm{Cu}$ (II) ions and its deposition in the body is poisonous and causes a severe impact like headache, gastrointestinal bleeding, kidney and liver failure and cancer. ${ }^{4,5}$ Thus, the elimination of $\mathrm{Cu}$ ions from water and wastewater is a significant for protection of the health and environment.

The pollution of water with dyes and metals is a severe problem for the public and the environment. Various industries like textiles, pharmacy, chemicals, coatings industry, metallurgy, pulp and paper, leather, paint, plastics and packaging devour an extensive quantity of chemical reagents and water through dyeing, processing and finishing activities. Dyes and metal ions are general pollutants for water because it is highly soluble. A severity 
of ecological problems occurs due to contamination of dyes and metal ions in the environment because it is difficult to degrade by biological methods. The elimination of pollutants like dyes, metals and pigments from wastewater is a significant for water pollution ${ }^{6}$.

A variety of procedures have been created for elimination of toxic pollutants from wastewater like ion exchange, flotation membrane filtration, electrochemical treatment, photocatalysis, chemical precipitation, and adsorption. ${ }^{7,8}$ Adsorption process is an effective, simple and useful method for of pollutant elimination ${ }^{9}$. Using a suitable adsorbent makes adsorption process suitable, low cost, ease of operation, versatility and an effective method for the elimination of dyes and metals from wastewater. The mainly significant advantages of the adsorbents are the amount of adsorbate that could rise on it.

Nowadays, nanocomposites have been widely used as adsorbent in environmental remediation for metal ions or dye removal with high adsorption capacity due to its suitable pore size, high mechanical strength, ease production, high selectivity and regeneration processes ${ }^{10}$. Recently, polymer-based nanocomposites developed owing to their advantages 1 film forming ability with variable dimensions and their high functionalities. ${ }^{11,12}$ Many polymer nanocomposites have widely utilized for elimination of a variety of toxic dyes, metal ions, and microorganism from water and wastewater for example: magnetic chitosan $/ \mathrm{Al}_{2} \mathrm{O}_{3} / \mathrm{Fe}_{3} \mathrm{O}_{4}$ nanocomposite for removing acid fuchsin dye, ${ }^{13}$ titanate layernatural polymer amylopectin based nanocomposite for adsorption and separation of $\mathrm{MB}$ and MO dyes, ${ }^{14}$ carboxymethyl-chitosan (CMC)/bentonite composite for adsorption of $\mathrm{Cu}^{2+}$ ions, ${ }^{15}$ polyaniline/carboxymethyl cellulose $/ \mathrm{TiO}_{2}$ nanocomposites $\left(\mathrm{PAn} / \mathrm{CMC} / \mathrm{TiO}_{2}\right)$ for adsorption of congo red dye, ${ }^{16} \mathrm{TiO}_{2}$-chitosan-polyacrylamide for the uptake of Sirius yellow $\mathrm{K}-\mathrm{CF}$ dye, ${ }^{17} \mathrm{TiO}_{2}$-Kaolinite nanocomposite for adsorption of $\mathrm{Pb}$ (II) and $\mathrm{Cd}(\mathrm{II})$ ions, ${ }^{18}$

Several methods used for the preparation of nanocomposite by incorporation of nanomaterials into a polymer through physical blending (mixing), crosslinking and polymerization reactions with monomers, solution casting method, hot press. ${ }^{19}$ Gamma radiation is one of the suitable methods for preparation of polymer metal nanocomposite by mixing the metal salt and organic monomer solution. During gamma irradiation and polymerization reaction, a homogeneous dispersion of nanocrystalline metal particles and polymerization of monomer created instantaneously, resulting in formation of in the polymer matrix. Many nanocomposites prepared by gamma radiation for different applications including different metal nanoparticles such as $\mathrm{Fe}_{3} \mathrm{O}_{4} . \mathrm{SiO}_{2}, \mathrm{TiO}_{2}, \mathrm{Au}, \mathrm{Ag}$, $\mathrm{PbO}$ and $\mathrm{Al}_{2} \mathrm{O}_{3}{ }^{20,21,22,23,24,25,26}$

Radiation is a convenient tool for the cross-linking and modification of polymeric materials without using cross-linking reagent. This technology is environmentally friendly since it leaves no residue or pollutant in the environment. ${ }^{27}$

PVA is a synthetic polymer soluble in water used in various industrial, pharmaceutical, medical, environmental and agricultural applications as a result of its low cost, chemical and physical resistance and amazing film forming property. ${ }^{28,29}$ Also, acrylamide (AAm) or acrylamide-based polymers is one of the water-soluble polymers that carry a negative charge and named anionic polyelectrolyte and used for a variety of applications in lubrication, effluent reclaiming, mining, Paper manufacture and water management process. ${ }^{30}$

One of the nanomaterials used in removal and adsorption of metals or dyes is to include titanium dioxide. $\mathrm{TiO}_{2}$ has been widely used owing to its low economic cost and high efficiency in pollution degradation. $\mathrm{TiO}_{2}$ can be used in many industrial applications like environmental purification, photovoltaic devices, solar energy conversion and optical coating photocatalysis.$^{31,32}$ 
In this study, gamma radiation synthesize of poly(vinyl alcohol)/polyacrylamide/ $/ \mathrm{TiO}_{2} / \mathrm{SiO}_{2}$ nanocomposites were obtained by polymerization of PVA and AAm in presence of $\mathrm{TiO}_{2} / \mathrm{SiO}_{2}$ nanoparticles at different irradiation doses for removal of $\mathrm{Cu}$ (II) ions and basic blue 3 dye from their aqueous solutions. The obtained nanocomposites were characterized by FTIR, XRD, SEM, EDS, TEM, and DLS. The batch adsorption experiments by studying the effect of a variety of conditions on dye or metal adsorption in addition to adsorption kinetics, sorption thermodynamic and adsorption isotherm models were also studied.

\section{Experimental}

\subsection{Chemicals}

Acrylamide (AAm) 97\%, was obtained from Pratap Chemical Industries, India. Poly(vinyl alcohol) (PVA), hydrochloric acid (36.5\%), sodium hydroxide was obtained from Qualikemes fine chemicals Pvt. Ltd. New Delhi, India, Nano-sized (10-20 nm) Titanium dioxide $\left(\mathrm{TiO}_{2}\right)$ and Silicon dioxide $\left(\mathrm{SiO}_{2}\right)$ of purity $99.5 \%$ were bought from Sigma Aldrich Chemie. Astrazon blue BG-200\% (Basic blue 3), was supplied by Dystar (Cairo, Egypt). NaOH were supplied by Merck Co., Germany.

\subsection{Radiation synthesis of PVA-co-AAm and PVA-co-AAm/ $/ \mathrm{TiO}_{2} / \mathrm{SiO}_{2}$ nanocomposites}

Firstly, $10.0 \mathrm{wt} \%$ of PVA-co-AAm copolymer was prepared by gamma radiationinduced copolymerization reaction at $30 \mathrm{kGy}$ via mixing of $5 \mathrm{wt} \%$ of PVA and $5 \mathrm{wt} \%$ of AAm solutions. Secondly, sonochemical followed by irradiation copolymerization techniques are used for synthesis of the PVA-co-AAm/ $/ \mathrm{TiO}_{2} / \mathrm{SiO}_{2}$ nanocomposites as follows: aqueous PVA/AAm solution were prepared by dissolving $4.75 \mathrm{~g}$ of PVA in $50 \mathrm{ml}$ of dist. water and $4.75 \mathrm{~g}$ of AAm in another $50 \mathrm{ml}$ dist. water under constant stirring at 70 ${ }^{\circ} \mathrm{C}$ for $4 \mathrm{~h}$. The two solutions were mixed, stirred and sonicated for $2 \mathrm{~h}$. Then, after complete dissolution of PVA/AAm solution, $0.25 \mathrm{~g}$ of $\mathrm{TiO}_{2}$ and $0.25 \mathrm{~g}$ of $\mathrm{SiO}_{2}$ were added to obtain a reactant mixture of $10 \mathrm{wt} \%$. The reactant mixture stirred for fully dispersion of $\mathrm{TiO}_{2} / \mathrm{SiO}_{2}$ nanoparticles using ultrasonic $(70 \mathrm{w})$ for $2 \mathrm{~h}$. Finally, after the reaction mixture was homogenized, the reactant mixtures bubbled by nitrogen gas for $5 \mathrm{~min}$, sealed and then polymerization was conducted by exposure to $\gamma$-rays $\left({ }^{60} \mathrm{Co}\right.$ Canadian) irradiation facility at different doses of $(10-50 \mathrm{kGy})$ at dose rate of $1.12 \mathrm{kGy} / \mathrm{h}$. The obtained PVA-co$\mathrm{AAm} / \mathrm{TiO}_{2} / \mathrm{SiO}_{2}$ nanocomposites washed well with ethanol to eliminate unreacted materials, dried at $60{ }^{\circ} \mathrm{C}$ and then grinded in a mortar to fine powder for further use and analysis.

\subsection{The gelation $(\%)$}

The dried PVA-co-AAm and PVA-co-AAm/TiO $/ 2 \mathrm{SiO}_{2}$ nanocomposites of known weights $\left(W_{i}\right)$ were soaked at $70^{\circ} \mathrm{C}$ in deionized water for $24 \mathrm{~h}$ to eliminate the insoluble parts. Then, dried to a constant weight $\left(W_{d}\right)$. The gelation $(\%)$ : established according to equation (1):

$$
\text { Gelation }(\%)=\frac{\left(W_{d}\right)}{\left(W_{i}\right)} \times 100
$$

\subsection{Swelling (\%):}

Known weights $\left(W_{d}\right)$ of dried PVA-co-AAm and PVA-co-AAm/TiO $/ \mathrm{SiO}_{2}$ nanocomposites were immersed in dist.water at room temperature until the equilibrium 
swelling was obtained after $24 \mathrm{~h}$. Then, samples weighed $(W s)$ after removing the excess water on their surfaces by a filter paper. The swelling (\%) was estimated according to equation (2):

$$
\text { Swelling }(\%)=\frac{\left(W_{s}-W_{d}\right)}{\left(W_{d}\right)} \times 100
$$

\subsection{Uptake of basic blue 3 dye or $\mathrm{Cu}$ (II) ions}

The effect of PVA-co-AAm, PVA-co-AAm $/ \mathrm{TiO}_{2} / \mathrm{SiO}_{2}$ nanocomposites (on adsorption and removal of basic blue 3 dye or $\mathrm{Cu}(\mathrm{II})$ ions as adsorbates was studied. Briefly, $0.1 \mathrm{~g}$ adsorbent amount was added to $50 \mathrm{ml}$ of aqueous solution of the dye or $\mathrm{Cu}$ (II) ions $(200 \mathrm{mg} / \mathrm{L})$ at room temperature for $24 \mathrm{~h}$ with shaking at agitation speed of 100 $\mathrm{rpm}$, then the decrease in UV absorbance was measured to detect the better adsorbent for further batch adsorption experiments. Secondly, the factors affecting the adsorption capacity of basic blue 3 dye or $\mathrm{Cu}$ (II) ions onto PVA-co-AAm/ $/ \mathrm{TiO}_{2} / \mathrm{SiO}_{2}-30$ nanocomposite was examined at varying the experimental conditions by using $50 \mathrm{ml}$ volume of dye or metal ions solution at time intervals up to $24 \mathrm{~h}$ as follows: (i) the effect of initial concentration (100-250 mg/L), (ii) the effect of adsorbent amount (0.1-0.4 g), (iii) the of effect of $\mathrm{pH}(4,7,9$ and 11 for dye; and 3, 4.5 and 6 for $\mathrm{Cu}$ (II) ions) and (iv) the effect of temperature at 298, 308 and $318 \mathrm{~K}$. After each experiment, the concentration of dye was determined by measuring its absorption at $\lambda_{\max }=654 \mathrm{~nm}$ by using T60 UV/Vis spectrophotometer from PG instruments limited. The remaining $\mathrm{Cu}$ (II) ions in the feed solution after adsorption was determined with atomic absorption spectrometer (AAS) Thermo scientific iCE 3000 series (AA) Spectrometer, Cambridge, England.

The adsorption kinetics, isotherm and thermodynamics study of dye and metal ions were evaluated. The calculation of adsorbed capacity $\left(\mathrm{q}_{\mathrm{e}}\right)$ at equilibrium and the amount adsorbed $\left(\mathrm{q}_{\mathrm{t}}\right)$ at time intervals was determined utilizing the following equations:-

$$
\begin{aligned}
& \text { Amount adsorbed }\left(q_{e}\right)=\frac{\left(C_{o}-C_{e}\right) \times V}{m} \\
& \text { Amount adsorbed }\left(q_{t}\right)=\frac{\left(C_{o}-C_{t}\right) \times V}{m}
\end{aligned}
$$

The removal (\%) was calculated using from equation (5) as follows:

$$
\text { Removal }(\%)=\frac{\left(C_{o}-C_{e}\right)}{C_{o}} \times 100
$$

Where $C_{0}, C_{t}$ and $C_{e}$ are the initial concentrations of dye or metal ions $(\mathrm{mg} / \mathrm{L})$ before adsorption, the concentration at time $(t)$ and the concentration at equilibrium, respectively, $m$ is the weight of dry adsorbent $(\mathrm{g})$.; $V$ is the volume of the aqueous dye or metal ions solution $(\mathrm{L})$;

\subsection{Characterization Analysis}

The chemical structure of the nanocomposites was analyzed by ATR-FTIR spectroscopy, Bruker Optik GmbH, Ettlingen, Germany. XRD-600 instrument with Ni filter and $\mathrm{Cu}-\mathrm{K} \alpha$ supplied From Shim Kyoto, Japan, used to obtain X-ray diffraction curves. The surface morphology of the copolymers and nanocomposites was investigated with SEM, 
JEOL JSM-5400, Japan.. Energy dispersive spectrometry (EDS) analysis LINK'S (Oxford Instruments link ISIS, UK) connected to scanning electron microscope model JEOL JSM5400 (Japan) was used to perform the consisting of the peaks belonging to the $\mathrm{C}, \mathrm{O}, \mathrm{Si}$ and Ti. The particle size and distibution examined using a Transmission Electron Microscopy (TEM), JEOL JSM-100 CX, Japan, with an acceleration voltage of 80KV. The distribution of particle of PVA-co-AAm/TiO $/ \mathrm{SiO}_{2}-30 \mathrm{kGy}$ nanocomposite was performed by dynamic light scattering (DLS-ZP/Particle Sizer Nicomp 380ZLS), USA. The effect of nanocomposites on the dye concentration was determined by measuring its absorption at $\lambda_{\max }=654 \mathrm{~nm}$ by utilizing the $\mathrm{T} 60 \mathrm{UV} / \mathrm{Vis}$ spectrophotometer from PG instruments limited.

\section{Results and Discussion}

3.1. The effect of irradiation dose on gelation (\%) and swelling (\%) of PVA-co-AAm / $\mathrm{TiO}_{2} / \mathrm{SiO}_{2}$ nanocomposites

Gamma irradiation is a useful crosslinking polymerization technique over other chemical cross-qlinker substances and an effective method to make polymeric nanocomposite. In this study, the copolymer prepared at $30 \mathrm{kGy}$ (PVA-co-AAm-30) and three PVA-co-AAm/ $/ \mathrm{TiO}_{2} / \mathrm{SiO}_{2}$ nanocomposites were prepared using the gamma irradiation technique at different doses of 10,30 and $50 \mathrm{kGy}$. Table 1 illustrated the impact of irradiation dose on gelation (\%) and swelling (\%) of PVA-co-AAm-30 copolymer and PVA-co-AAm $/ \mathrm{TiO}_{2} / \mathrm{SiO}_{2}$ nanocomposites. The increase in irradiation dose from $10 \mathrm{kGy}$ to $50 \mathrm{kGy}$ doses do not lead to significant increase in gelation (\%) and it was in the range of 90.8 to $95.7 \%$. This is due to increasing the cross-linking reaction between PVA-co-AAm upon effect of the gamma irradiation. Also, PVA-co-AAm/ $/ \mathrm{TiO}_{2} / \mathrm{SiO}_{2}-30$ had the highest swelling $(\%)$ of $197.7 \%$ then decreases at $50 \mathrm{kGy}$ due to the increase in crosslinking density.

Table 1: The impact of irradiation dose on gelation (\%) and swelling (\%) of PVA-coAAm-30 and PVA-co-AAm/ $\mathrm{TiO}_{2} / \mathrm{SiO}_{2}$ nanocomposites.

\begin{tabular}{lccl}
\hline \multicolumn{1}{c}{$\begin{array}{c}\text { Sample } \\
\text { key }\end{array}$} & $\begin{array}{c}\text { Dose } \\
(\mathrm{kGy})\end{array}$ & $\begin{array}{c}\text { Gelation } \\
(\%)\end{array}$ & Swelling (\%) \\
\hline PVA-co-AAm-30 & 30 & 89.6 & 204.3 \\
PVA-co-AAm/TiO $/ \mathrm{SiO}_{2}-10$ & 10 & 90.8 & 165.5 \\
PVA-co-AAm $/ \mathrm{TiO}_{2} / \mathrm{SiO}_{2}-30$ & 30 & 93.1 & 197.7 \\
PVA-co-AAm $/ \mathrm{TiO}_{2} / \mathrm{SiO}_{2}-50$ & 50 & 95.7 & 143.6 \\
\hline
\end{tabular}

\subsection{Characterization analysis}

\subsubsection{FT-IR investigation}

Figure 1 illustrates the FT-IR spectrum of PVA, AAm and the synthesized kGy nanocomposite. The spectrum of PVA (Figure 1a) demonstrates at $3290 \mathrm{~cm}^{-1}$ and $2923 \mathrm{~cm}^{-1}$ related to the $-\mathrm{OH}$ and $\mathrm{C}-\mathrm{H}$ alkyl, respectively. Stretching vibration peaks correspond to $\mathrm{C}-\mathrm{O}$ and $\mathrm{C}=\mathrm{O}$ from residual ester groups appear at $1427 \mathrm{~cm}^{-1}$ and $1728 \mathrm{~cm}^{-1}$, respectively. Also, the stretching vibrations peaks characteristic to $\mathrm{C}-\mathrm{O}$ and $\mathrm{C}-\mathrm{O}-\mathrm{C}$ appear at $1024 \mathrm{~cm}^{-1}$ and $1092 \mathrm{~cm}^{-1}$, respectively. ${ }^{33}$

The FTIR spectrum of AAm Figure $1 \mathrm{~b}$ shows the peaks at $1603 \mathrm{~cm}^{-1}$ and $1656 \mathrm{~cm}^{-1}$ corresponding to bending vibration of the $-\mathrm{NH}_{2}$ group and stretching vibrations of the $\mathrm{C}=\mathrm{O}$ group, respectively. The peaks at $1421 \mathrm{~cm}^{-1}$ and $1467 \mathrm{~cm}^{-1}$ resulted from the scissor 
and bending vibrations of $\mathrm{CH}-\mathrm{CO}$ and $-\mathrm{CH}_{2}$ groups, respectively. Additionally, the absorption peak attributed to the stretching vibrations of $-\mathrm{CH}_{2}$ appear at $2811 \mathrm{~cm}^{-1}$. A broad absorption band resulted from the $-\mathrm{NH}$ group appear at $3160 \mathrm{~cm}^{-1}$ and $3333 \mathrm{~cm}^{-1}$. Finally, the absorption stretching vibration band from $\mathrm{C}-\mathrm{N}$ group resulted at $1346 \mathrm{~cm}^{-1}$, while the broad absorption bands resulted from the out of plane bending vibration of $\mathrm{NH}_{2}$ group appears in the range of $619-655 \mathrm{~cm}^{-1}$ were.

The FT-IR spectrum of PVA-co-AAm/ $/ \mathrm{TiO}_{2} / \mathrm{SiO}_{2}$ nanocomposite. Figure 1c shows stretching vibration peaks characteristic to the $\mathrm{C}=\mathrm{O}$ of amide $\mathrm{I}$ and $\mathrm{N}-\mathrm{H}$ bending vibration at $1720 \mathrm{~cm}^{-1}$ and $1661 \mathrm{~cm}^{-1}$, respectively. ${ }^{34}$ Moreover, a minor peak shift and broadening appeared at $3340 \mathrm{~cm}^{-1}$ due to the overlapping of $-\mathrm{NH}$ groups of AAm and -OH of PVA stretching vibrations forming a hydrogen bonding between them. These results indicated the successful grafting of AAM onto the PVA backbone. ${ }^{35}$ The stretching vibration peaks related to the Ti-O-Ti resulted in the range $557-752 \mathrm{~cm}^{-1}$. The stretching vibrations absorption bands resulted from Si-O-Si and Si-O-H appeared at $932 \mathrm{~cm}^{-1}$ and $1094 \mathrm{~cm}^{-1}$ respectively.

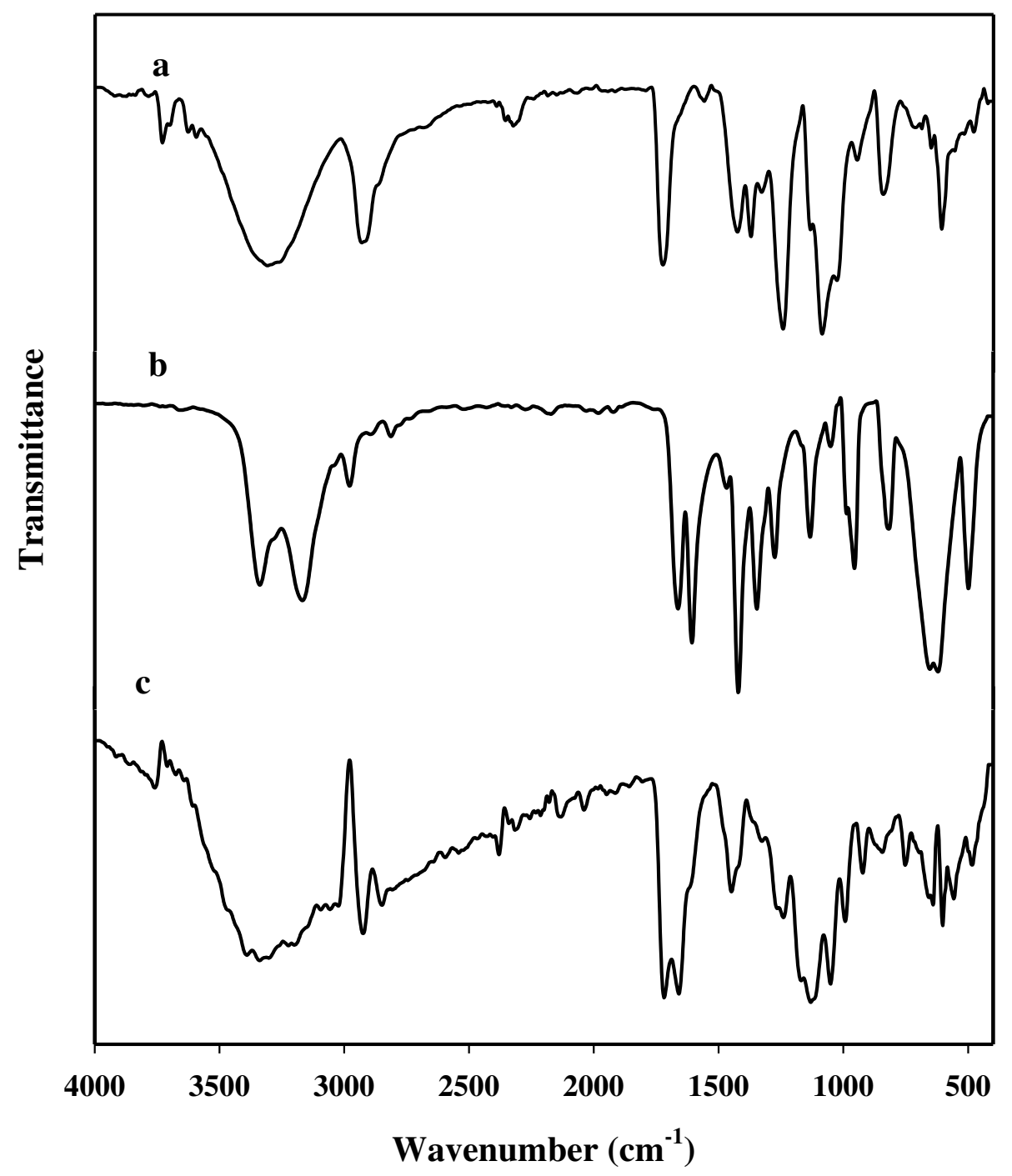

Figure 1:- FTIR spectra of (a) PVA, (b) AAm and (c) PVA-co-AAm/ $/ \mathrm{TiO}_{2} / \mathrm{SiO}_{2}$ nanocomposite. 


\subsubsection{XRD studies}

$\mathrm{X}$-ray diffraction is an important tool, which provides the crystallinity and lattice structure of nanocomposite. Figure 2 shows the XRD measurements and the crystalline structure of PVA-co-AAm, and PVA-co-AAm/TiO $/ \mathrm{SiO}_{2}$ nanocomposites prepared at different doses of 10, 30 and $50 \mathrm{kGy}$. Figure 2a shows XRD of PVA-co-AAm showed semi-crystalline peaks at the $2 \theta=19.1^{\circ} .{ }^{36}$ The XRD curves of PVA-co-AAm $/ \mathrm{TiO}_{2} / \mathrm{SiO}_{2}$ nanocomposite prepared at different doses of 10,30 and $50 \mathrm{kGy}$ (Figure 2b-d) illustrate the same diffraction peaks of PVA-co-AAm with small shift at $2 \theta=19.1^{\circ}$ which is attributed to the presence of $\mathrm{TiO}_{2}$ and $\mathrm{SiO}_{2}$ in addition to the diffraction peak of $\mathrm{SiO}_{2}$ overlapped with the diffraction peak of PVA-co-AAm at $2 \theta=19.1^{\circ}$. The characteristic peaks of $\mathrm{TiO}_{2}$ nanoparticles observed at $2 \theta=25.1^{\circ}, 37.6^{\circ}, 47.9^{\circ}, 53.7^{\circ}, 55.1^{\circ}, 62.6^{\circ}, 68.3^{\circ}, 69.9^{\circ}$ and $74.9^{\circ}$ which confirms the spinal structure of the Bragg reflections of anatase phase of $\mathrm{TiO}_{2}$ nanoparticles corresponding to the crystal planes of the (A101), (A004), (A200), (A105), (A211), (A118), (A116) and (A220), respectively. In addition, the peaks at $27^{\circ}, 36.2^{\circ}$ and $55.0^{\circ}$ corresponding to the crystal planes of the (R110), (R101) and (R211) which corresponds to $\mathrm{TiO}_{2}$ in the rutile phase. All peaks are well agreement with the standard spectrum (JCPDS no.: 21-1272, 88-1175 for rutile and 84-1286 for anatase) ${ }^{37}$ In the XRD spectra, the characteristic peak at $2 \theta=25.10^{\circ}$ and $27^{\circ}$ signifies the existence of $\mathrm{TiO}_{2}$, which compatible with the composition of $80 \%$ anatase and $20 \%$ rutile. ${ }^{38}$ The majority structure of $\mathrm{TiO}_{2}$ in anatase phase candidate their possible use as an effective adsorbent for adsorption process of metal ions and dyes. 


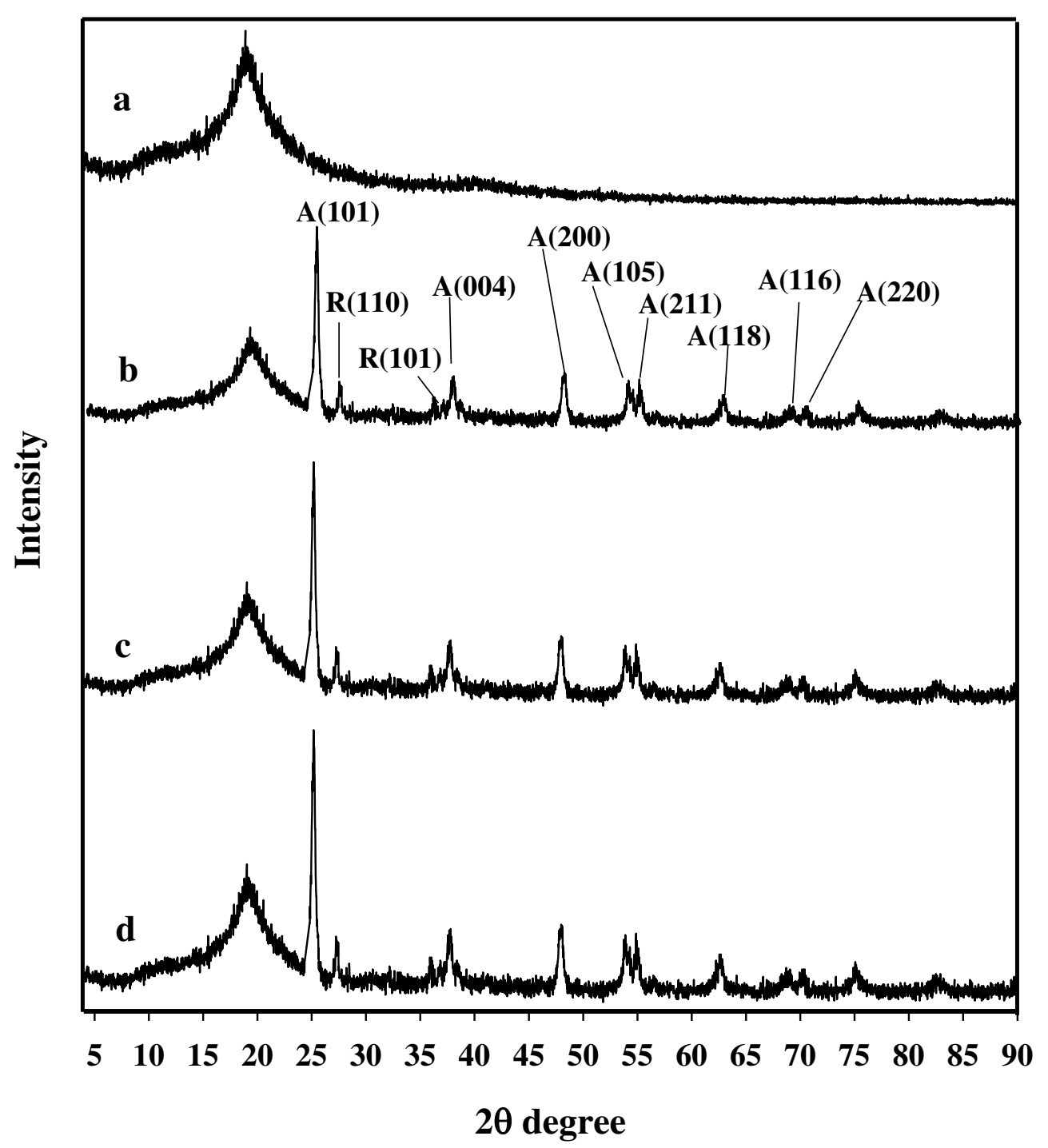

Figure 2:- XRD curves of (a) PVA-co-AAm, (b) PVA-co-AAm/TiO $/ \mathrm{SiO}_{2}-10$ (c) PVA-co$\mathrm{AAm} / \mathrm{TiO}_{2} / \mathrm{SiO}_{2}-30$ and (d) PVA-co-AAm/ $/ \mathrm{TiO}_{2} / \mathrm{SiO}_{2}-50$ nanocomposites.

\subsubsection{TEM and DLS analysis}

Figure 3 shows TEM images of PVA-co-AAm/ $/ \mathrm{TiO}_{2} / \mathrm{SiO}_{2}$ prepared at different irradiation doses of 10, 30 and $50 \mathrm{kGy}$. Generally, bright images of $\mathrm{TiO}_{2}$ and $\mathrm{SiO}_{2}$ nanoparticles with spherical shape embedded in a gray shell of PVA-co-AAm molecules with an average size of 60-70 nm. In addition, the $\mathrm{TiO}_{2}$ and $\mathrm{SiO}_{2}$ nanoparticles were dispersed well of good uniform distribution with no agglomeration. It was noticed that the irradiation dose affect TEM results. With increasing the irradiation dose during the preparation of nanocomposite, the high dispersion of $\mathrm{TiO}_{2} / \mathrm{SiO}_{2}$ nanoparticles inside the nanocomposite especially that prepared at $50 \mathrm{kGy}$ (Figure 3c). The particle size distribution of PVA-co-AAm/ $/ \mathrm{TiO}_{2} / \mathrm{SiO}_{2}-$ 30 (Figure 3d) obtained from DLS was homogeneously shape with an average size of about $93.5 \mathrm{~nm}$ which is large and nearly close to the TEM characterization due to the association and aggregation molecules of nanocomposite in aqueous media via Vander Waal's force or hydrogen bonding. 


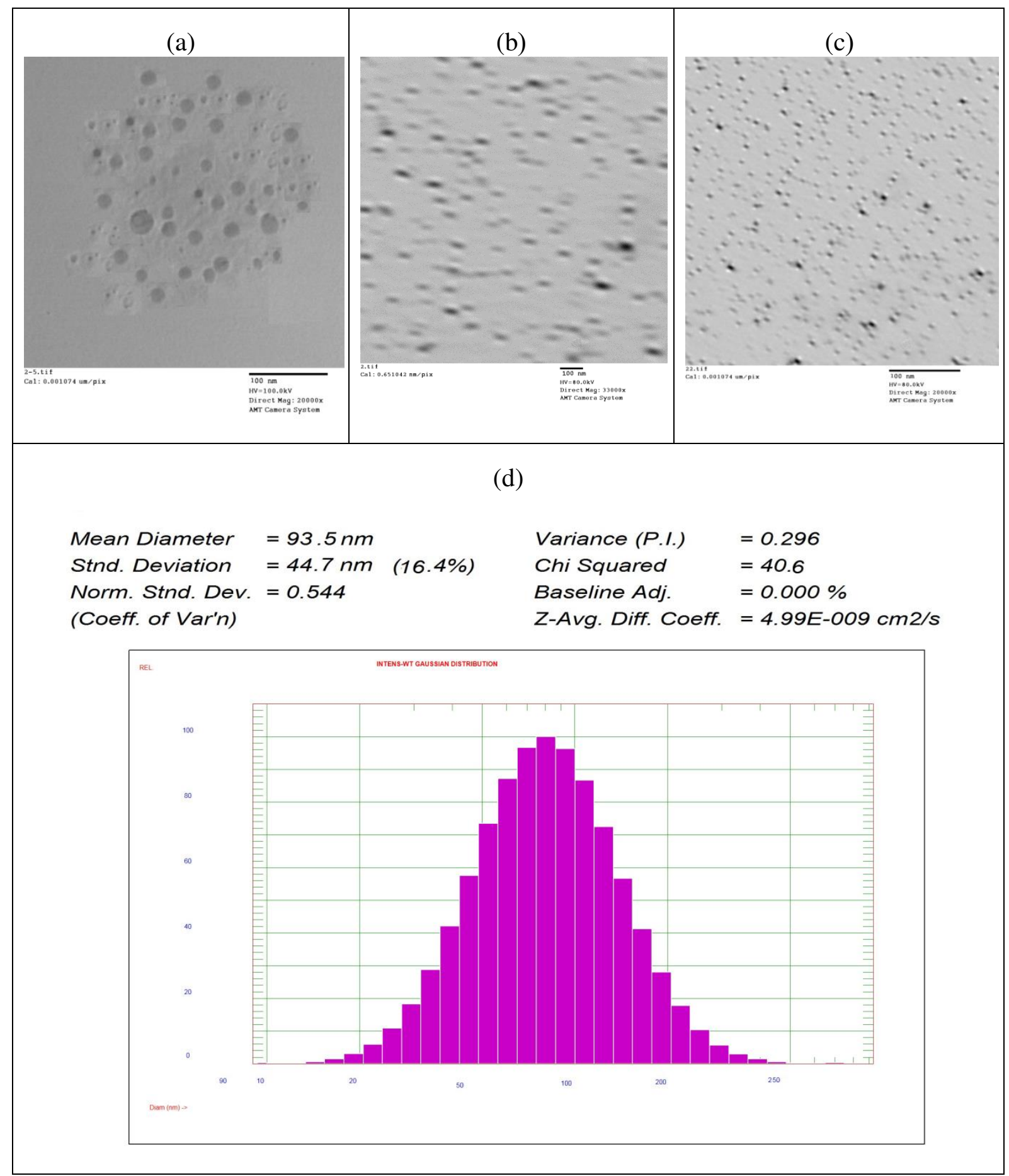

Figure 3:- TEM images of (a) PVA-co-AAm/TiO $/ \mathrm{SiO}_{2}-10$, (b) PVA-co-AAm/ $/ \mathrm{TiO}_{2} / \mathrm{SiO}_{2}-$ 30 and (c) PVA-co-AAm/ $/ \mathrm{TiO}_{2} / \mathrm{SiO}_{2}-50$. (d) DLS of PVA-co-AAm/ $/ \mathrm{TiO}_{2} / \mathrm{SiO}_{2}-$ 30 nanocomposite. 


\subsubsection{SEM and EDX analysis}

Figure 4 shows the changes in surface morphology of PVA-co-AAm/ $/ \mathrm{TiO}_{2} / \mathrm{SiO}_{2}$ nanocomposites investigated by SEM. Figure 4a shows SEM micrograph of PVA-co$\mathrm{AAm} / \mathrm{TiO}_{2} / \mathrm{SiO}_{2}-10$ had a rocky shape, possess a highly porous structure with white spots and tightly packaged on the back-scattered image seem to be agglomerates particle coated composite surface. While, SEM of PVA-co-AAm/TiO $/ \mathrm{SiO}_{2}-30$ (Figure $4 \mathrm{~b}$ ) and PVA-co$\mathrm{AAm} / \mathrm{TiO}_{2} / \mathrm{SiO}_{2}-50$ (Figure $4 \mathrm{c}$ ) has coarse surface and in close contact with one another due to increasing the crosslinking of PVA-co-AAm and the formation of semiinterpenetrating crosslinked network. In addition, the $\mathrm{TiO}_{2} / \mathrm{SiO}_{2}$ nanoparticles well distributed on their surfaces. To confirm the presence of all the mentioned elements including $\mathrm{Si}, \mathrm{Ti}, \mathrm{C}$ and $\mathrm{O}$ in the synthesized nanocomposites, elemental analysis was performed on the sample using EDX analysis. Figure 4d demonstrates the EDX analysis of PVA-co-AAm/ $/ \mathrm{TiO}_{2} / \mathrm{SiO}_{2}$ nanocomposite consisting of the peaks belonging to the $\mathrm{C}, \mathrm{O}, \mathrm{Si}$ and $\mathrm{Ti}$ were exactly determined. A mostly intense peak of $\mathrm{C}$ is originated from PVA and AAm. $\mathrm{O}$ is originated from PVA, AAm, $\mathrm{TiO}_{2}$, and $\mathrm{SiO}_{2}$. The result revealed that $\mathrm{Ti}$ is detected at 4.5-5.0 KeV and $\mathrm{Si}$ is detected at $1.8 \mathrm{KeV}$. 


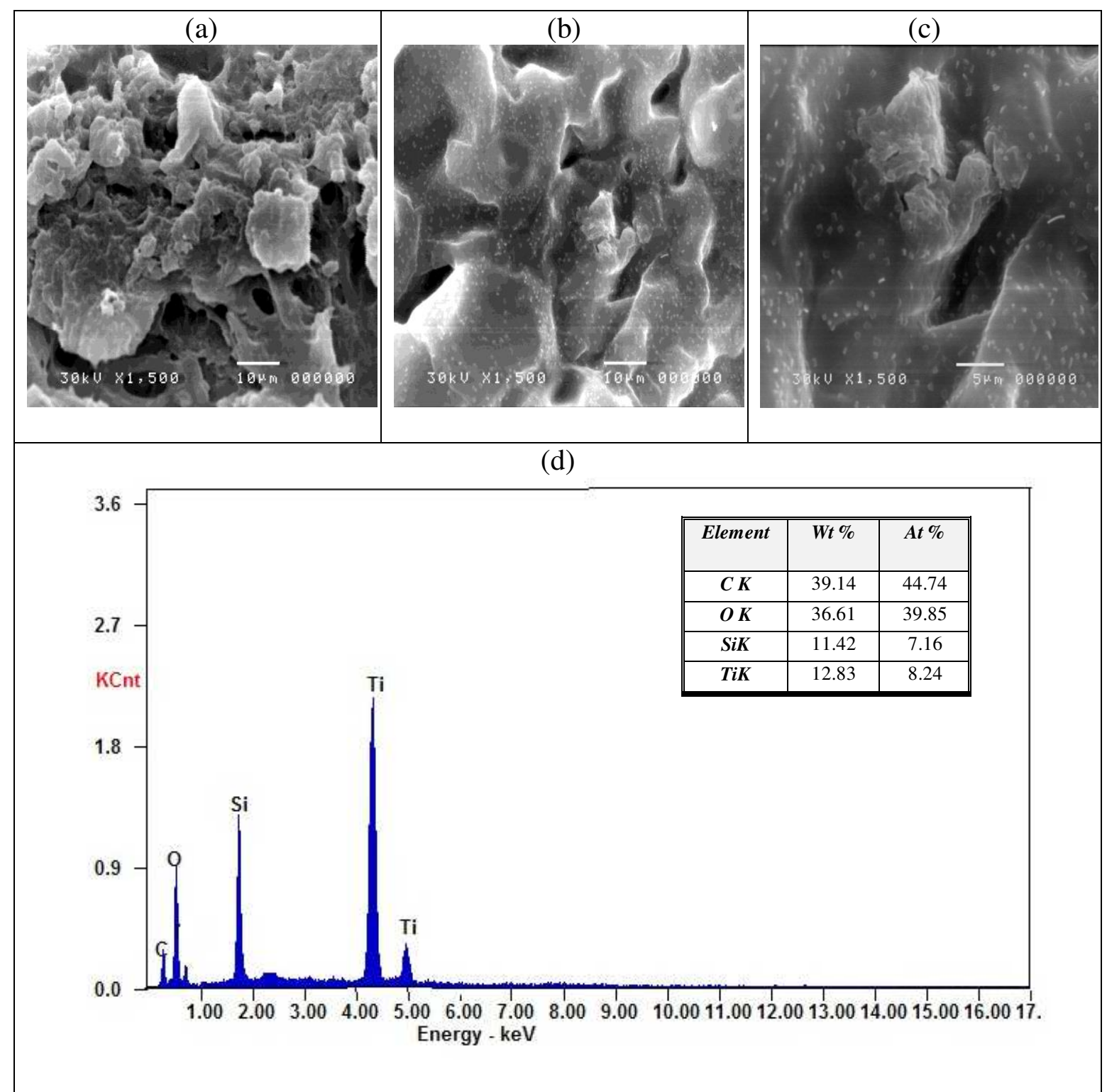

Figure 4: $\quad$ SEM micrographs of(a) PVA-co-AAm/ $/ \mathrm{TiO}_{2} / \mathrm{SiO}_{2}-10$ (b) $\mathrm{PVA}$-co$\mathrm{AAm} / \mathrm{TiO}_{2} / \mathrm{SiO}_{2}-30$ and (c) PVA-co-AAm $/ \mathrm{TiO}_{2} / \mathrm{SiO}_{2}-50$.(d) SEM/EDX spectrum of PVA-co-AAm/ $/ \mathrm{TiO}_{2} / \mathrm{SiO}_{2}-30$ nanocomposite.

\section{3. uptake of dye and heavy metal ions}

\subsubsection{Impact of irradiation dose}

Figure 5 shows the UV absorbance of basic blue 3 dye and $\mathrm{Cu}$ (II) ions after treatment by PVA-co-AAm and PVA-co-AAm/ $/ \mathrm{TiO}_{2} / \mathrm{SiO}_{2}$ nanocomposites prepared at different irradiation doses of 10,30 and $50 \mathrm{kGy}$. The results show that the PVA-co$\mathrm{AAm} / \mathrm{TiO}_{2} / \mathrm{SiO}_{2}$ nanocomposites had uptake affinity towards metal ions as well as the dye investigated.

The prepared nanocomposites showed high adsorption capacity compared by PVAco-AAm. The presence of $\mathrm{TiO}_{2} / \mathrm{SiO}_{2}$ nanoparticles increases the amount of uptake of dye or $\mathrm{Cu}$ (II) 3 folds. Also, the PVA-co-AAm/TiO $/ 2 / \mathrm{SiO}_{2}-30$ and PVA-co-AAm/ $/ \mathrm{TiO}_{2} / \mathrm{SiO}_{2}-50$ showed high adsorption capacity. However, PVA-co-AAm/ $/ \mathrm{TiO}_{2} / \mathrm{SiO}_{2}-30$ shows high swelling (\%) as the results obtained from Table 1, and it was selected for further adsorption experiments. 

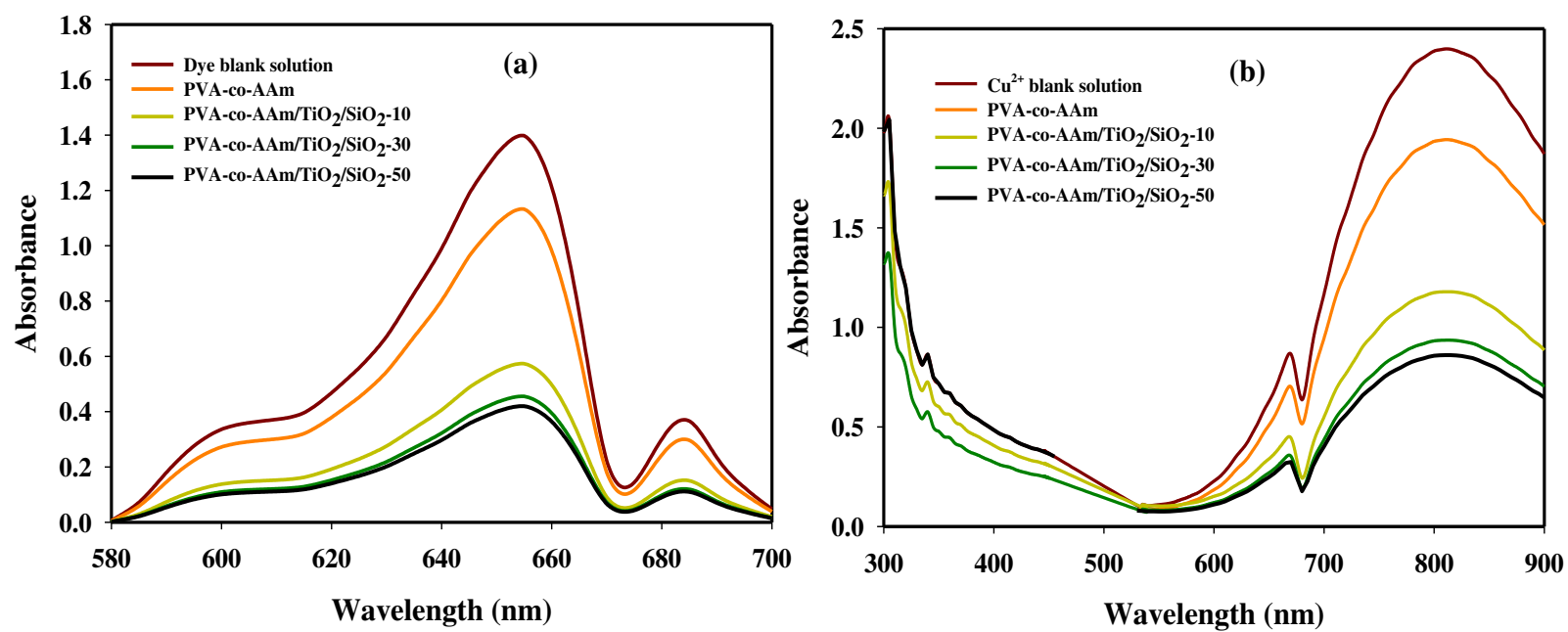

Figure (5): UV absorption spectra of (a) basic blue 3 dye and (b) $\mathrm{Cu}$ (II) ions by the effect of the prepared PVA-co-AAm and PVA-co-AAm/ $\mathrm{TiO}_{2} / \mathrm{SiO}_{2}$ nanocomposites.

\subsubsection{Effect of $\mathbf{p H}$}

The effect of initial $\mathrm{pH}(4,7,9$ and 11) and $\mathrm{pH}(3,4.5$ and 6$)$ on the adsorption capacity and removal (\%) of basic blue 3 dye and $\mathrm{Cu}(\mathrm{II})$ ions, respectively by PVA-co$\mathrm{AAm} / \mathrm{TiO}_{2} / \mathrm{SiO}_{2}-30$ nanocomposite as a function of various contact time up to $24 \mathrm{~h}$ was investigated in Figure 6.

Generally, the removal (\%) of $\mathrm{Cu}(\mathrm{II})$ ions and basic blue 3 dye increased as the $\mathrm{pH}$ increases. Also, the removal (\%) for the adsorbed dye (figure 6a) or $\mathrm{Cu}$ (II) ions (Figure 6b) increases as the contact time increases and reaches the equilibrium adsorption after $7 \mathrm{~h}$ for basic blue 3 dye and $6 \mathrm{~h}$ for $\mathrm{Cu}$ (II) ions. However, as the contact time increased to $24 \mathrm{~h}$, the amount of both dye and $\mathrm{Cu}(\mathrm{II})$ ions adsorbed onto nanocomposite surface increases slightly. This is owing to the saturation of available surface sites of the nanocomposite. Therefore, the optimized $\mathrm{pH}$ for high adsorption noticed at $\mathrm{pH} 11.0$ for basic blue 3 dye and at 6.0 for $\mathrm{Cu}$ (II) ions and for the next batch experiments. The removal (\%) for basic blue 3 dye and $\mathrm{Cu}$ (II) ions was and $83.14 \%$ and $95.42 \%$ at the optimum $\mathrm{pH}$, respectively.

Figure $6 \mathrm{~b}$ shows that the adsorption of $\mathrm{Cu}(\mathrm{II})$ was profoundly dependent on $\mathrm{pH}$, since $\mathrm{pH}$ influences the solubility of $\mathrm{Cu}(\mathrm{II})$ ions and the ionization state of the $-\mathrm{OH}$ and $\mathrm{CONH}_{2}$ groups in the PVA-co- $\mathrm{AAm} / \mathrm{TiO}_{2} / \mathrm{SiO}_{2}-30$ nanocomposite. In addition, the increase in $\mathrm{pH} \mathrm{Cu}$ (II) ions ( $>6.0$ ) was restricted to avoid the creation of copper hydroxide. The adsorption of the basic blue 3 dye and $\mathrm{Cu}$ (II) ions is low at $\mathrm{pH}<6$. This demonstrates that the solution acidity reduces the basic blue 3 dye and $\mathrm{Cu}$ (II) ions adsorption. This behavior could be explained based on change in the surface charge of PVA-co$\mathrm{AAm} / \mathrm{TiO}_{2} / \mathrm{SiO}_{2}-30$ nanocomposite. In acidic solution, the active groups of PVA-co$\mathrm{AAm} / \mathrm{TiO}_{2} / \mathrm{SiO}_{2}-30$ nanocomposite such as hydroxyl and amide groups are protonated and competition between $\mathrm{H}^{+}$and both basic blue 3 dye and $\mathrm{Cu}(\mathrm{II})$ ions for adsorption sites led to little adsorption of metal ion or dye. Meanwhile, as the $\mathrm{pH}$ increases, deprotonation of the functional groups occur and the PVA-co-AAm/ $/ \mathrm{TiO}_{2} / \mathrm{SiO}_{2}-30$ nanocomposite surface charge became negative, which prompted advanced adsorption of cationic species. 

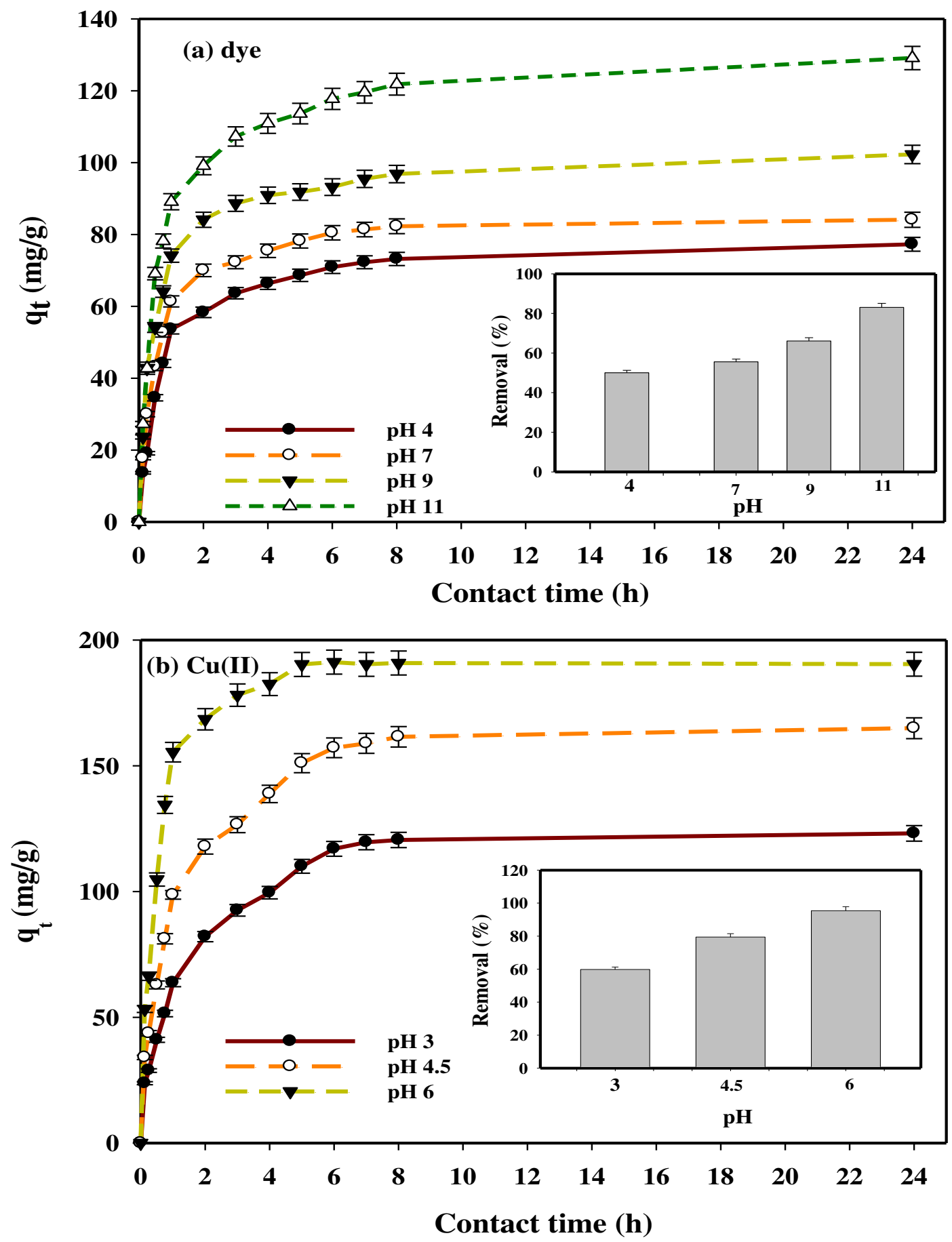

Figure (6): Effect of $\mathrm{pH}$ and contact time (h) on the amount adsorbed $\left(\mathrm{q}_{\mathrm{t}}\right)(\mathrm{mg} / \mathrm{g})$ and removal (\%) of (a) basic blue 3 dye and (b) $\mathrm{Cu}$ (II) ions onto PVA-co-AAm/ $/ \mathrm{TiO}_{2} / \mathrm{SiO}_{2}$ nanocomposite (initial concentration $150 \mathrm{mg} / \mathrm{L}$ for the dye and $200 \mathrm{mg} / \mathrm{L}$ for $\mathrm{Cu}$ (II) ions; adsorbent dosage $0.3 \mathrm{~g}$; temperature $298 \mathrm{~K}$; agitation speed $100 \mathrm{rpm}$ ). 


\subsubsection{Impact of adsorbent dosage}

The impact of PVA-co-AAm/ $/ \mathrm{TiO}_{2} / \mathrm{SiO}_{2}-30$ nanocomposite dosage $(0.1-0.4 \mathrm{~g})$ on the amount adsorbed of basic blue 3 dye and $\mathrm{Cu}(\mathrm{II})$ ions was considered and the obtained data are presented in Figure 7. The results demonstrate that the removal efficiency (\%) regularly increased as the contact time and adsorbent dosage increase and attained the highest values of $93.6 \%$ and $98.7 \%$ for basic blue 3 dye and $\mathrm{Cu}(\mathrm{II})$ ions, respectively with adsorbent dosage $0.3 \mathrm{~g}$ of PVA-co-AAm/ $/ \mathrm{TiO}_{2} / \mathrm{SiO}_{2}-30$ nanocomposite. However, the saturated removal (\%) occurred nearly at $0.3 \mathrm{~g}$ after contact time nearly $7 \mathrm{~h}$ for dye and $6 \mathrm{~h}$ for $\mathrm{Cu}(\mathrm{II})$, then extra increase in dosage gives a small increase in basic blue 3 dye or $\mathrm{Cu}(\mathrm{II})$ ions adsorption. Thus, $0.3 \mathrm{~g}$ of PVA-co-AAm/ $/ \mathrm{TiO}_{2} / \mathrm{SiO}_{2}-30$ nanocomposite was chosen to be the optimum dosage for the additional adsorption studies. As the adsorbent mass increases, the adsorption increases that attributed to the increased surface area and consequence the availability of more sites for adsorption. Also, as the contact time increases the adsorption capacity increases, designates that the equilibrium adsorption was about (123.9 mg/g and 82.6 Removal \%) for basic blue 3 dye and (190.3 mg/g and removal $95.1 \%$ ) for $\mathrm{Cu}$ (II) ions after about $7 \mathrm{~h}$ and $6 \mathrm{~h}$ contact time, respectively. 

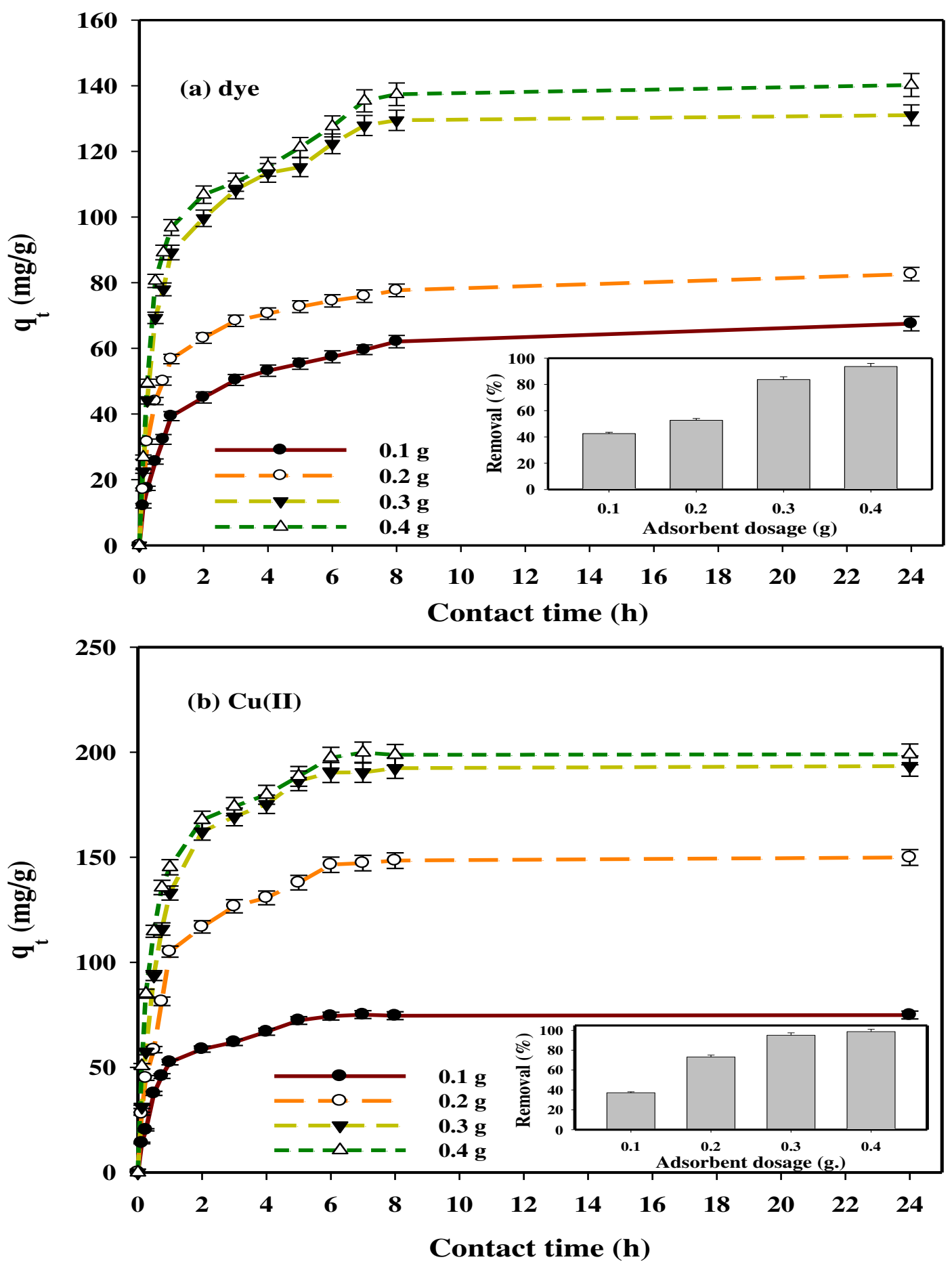

Figure (7): Effect of adsorbent dosages and contact time (h) on the amount adsorbed $\left(\mathrm{mg} / \mathrm{g}\right.$ ) of the (a) basic blue 3 dye and (b) $\mathrm{Cu}$ (II) ions onto the PVA-co-AAm/ $/ \mathrm{TiO}_{2} / \mathrm{SiO}_{2}-30$ nanocomposite ( $\mathrm{pH} 11$ for the dye and $\mathrm{pH} 6$ for $\mathrm{Cu}$ (II); initial concentration $150 \mathrm{mg} / \mathrm{L}$ for the dye and $200 \mathrm{mg} / \mathrm{L}$ for $\mathrm{Cu}$ (II) ions; temperature $298 \mathrm{~K}$; agitation speed $100 \mathrm{rpm}$ ). 


\subsubsection{Effect of initial concentration}

One of the effective parameters on the adsorption efficiency is the initial concentration of metal ions or dye. The effect of initial concentration (100, 150, 200, and $250 \mathrm{mg} / \mathrm{L}$ ) of basic blue 3 dye or $\mathrm{Cu}(\mathrm{II})$ ions on the adsorption efficiency and removal (\%) as a function of various contact times up to $24 \mathrm{~h}$ onto the PVA-co-AAm/TiO $/ \mathrm{SiO}_{2}-30$ nanocomposite was studied as illustrated in Figure 8.

The results of adsorption demonstrate that the adsorption capacity and the removal (\%) of both dye and $\mathrm{Cu}(\mathrm{II})$ ions onto the nanocomposite enhanced strongly with the increase in the initial concentration to $150 \mathrm{mg} / \mathrm{L}$ for the dye and to $200 \mathrm{mg} / \mathrm{L}$ for $\mathrm{Cu}$ (II). This enhancement in adsorption efficiency may be because of existing adsorption active sites of PVA-co-AAm/ $/ \mathrm{TiO}_{2} / \mathrm{SiO}_{2}-30$ nanocomposite are available at low initial concentration, thus resulting in an increase of uptake percentage. At higher concentrations of dye or metal ions, the ratio of the existing surface of nanocomposite to the initial dye or metal ions concentration is minor; consequently, the removal $(\%)$ becomes reliant on initial concentrations. ${ }^{39}$ However, the adsorption capacity $(\mathrm{mg} / \mathrm{g})$ of the dye or the metal ions increased with increasing their initial concentrations. The maximum adsorption capacity of basic blue 3 dye and $\mathrm{Cu}$ (II) ions noticed at 123.9 and $190.3 \mathrm{mg} / \mathrm{g}$, respectively. From the acquired outcomes, it was apparent that PVA-co-AAm/ $/ \mathrm{TiO}_{2} / \mathrm{SiO}_{2}-30$ nanocomposite exhibited strong affinity towards $\mathrm{Cu}$ (II) ions than dye. This is because of the variation in the charge density and the size of the dye and $\mathrm{Cu}$ (II) ions. $\mathrm{Cu}$ (II) ions have greater charge density and smaller size rather than the dye and have a strong attraction to the oxygen and nitrogen atoms lone pair electrons in the hydroxyl and amide groups of nanocomposite forming stable complexes. 

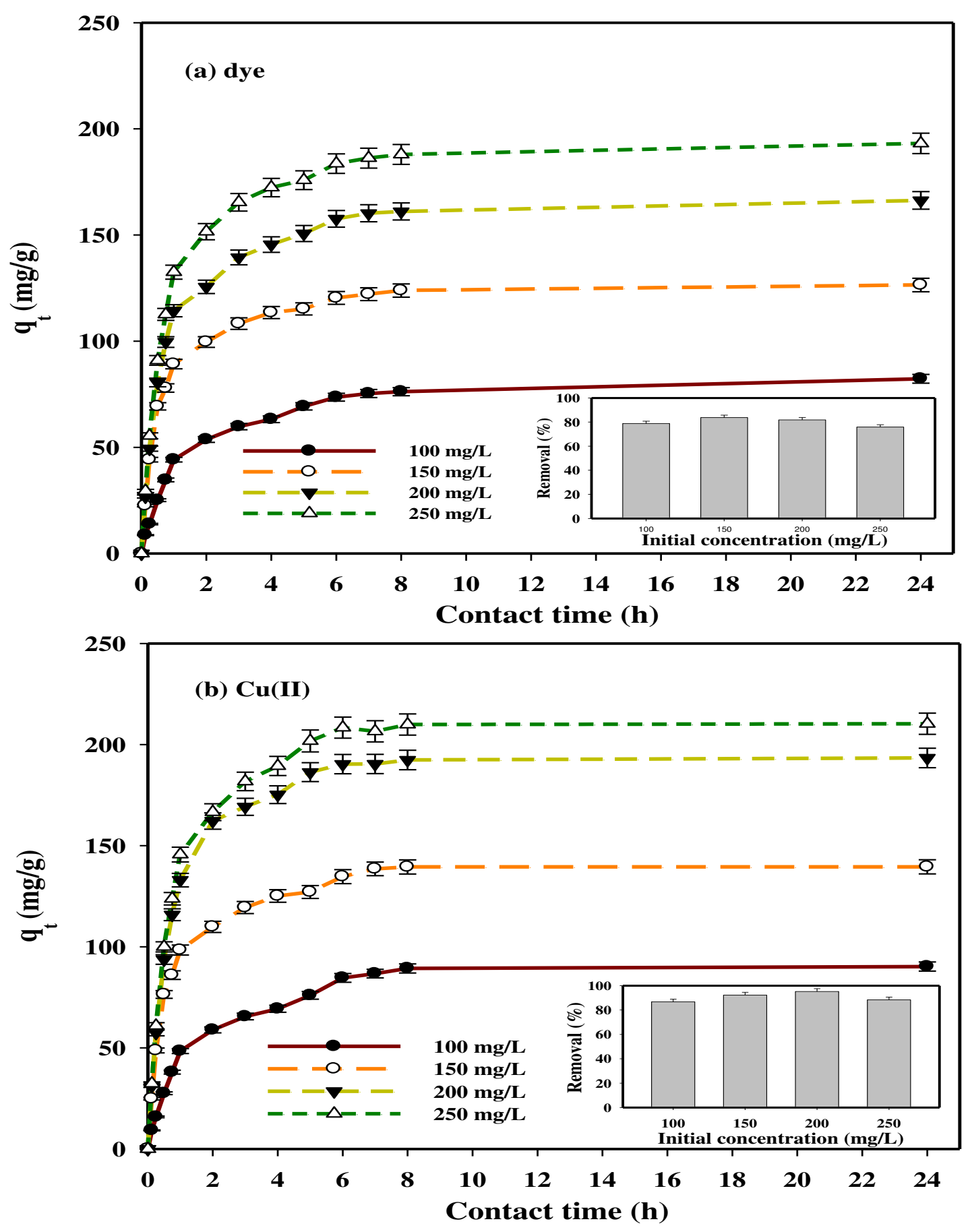

Figure (8):- Impact of initial concentration (mg/l) with contact time (h) onto the amount adsorbed (mg/g) and removal (\%) of the (a) basic blue 3 dye and (b) $\mathrm{Cu}$ (II) ions onto the PVA-co-AAm/ $/ \mathrm{TiO}_{2} / \mathrm{SiO}_{2}-30$ nanocomposite (pH 11 for the dye and $\mathrm{pH} 6$ for $\mathrm{Cu}$ (II), $0.3 \mathrm{~g}$ adsorbent dosage. temperature $298 \mathrm{~K}$; agitation speed $100 \mathrm{rpm}$ ). 


\subsubsection{Impact of temperature}

Temperature is a significant factor in the strategy of dye or metal ions adsorption and considered as an important factor to study their thermodynamic behaviors to detect whether the adsorption performance is an exothermic or endothermic reaction. Figure 9 represents the relationship between the temperature dependence and the amount adsorbed $(\mathrm{mg} / \mathrm{g})$ or removal $(\%)$ of the basic blue 3 dye and $\mathrm{Cu}$ (II) ions and onto the PVA-co$\mathrm{AAm} / \mathrm{TiO}_{2} / \mathrm{SiO}_{2}-30$ nanocomposite was performed at 298,308 and $318 \mathrm{~K}$. It is noticed that the amount of adsorption $(\mathrm{mg} / \mathrm{g})$ and removal $(\%)$ of both dye and metal ions increases with increasing temperature from 298 to $318 \mathrm{~K}$. The adsorption capacities of the prepared nanocomposite on the dye increased from 117.1 to $123.9 \mathrm{mg} / \mathrm{g}$ for the dye and increased from 190.3 to $196.6 \mathrm{mg} / \mathrm{g}$ for $\mathrm{Cu}$ (II) ions. This is attributed to the increment in the kinetic energy of the adsorbent molecules with the increment in temperature, the increased activated sites created on the PVA-co- $\mathrm{AAm} / \mathrm{TiO}_{2} / \mathrm{SiO}_{2}-30$ nanocomposite and the increase in kinetic motion of metal ion molecules that leads to increase the penetration of metal ions inside the micropores of the prepared nanocomposite as temperature increased. Also, with increasing the temperature, the speed of diffusion of dye molecules through the exterior boundary layer and in the interior holes in the nanocomposite increases with the temperature and the amount of the adsorbed $\mathrm{Cu}$ (II) ions or the dye adsorption increases. The results revealed that the adsorption process is an endothermic reaction and prepared nanocomposite is a successful adsorbent for the adsorption of basic blue 3 dye or $\mathrm{Cu}$ (II) ions from wastewater. 

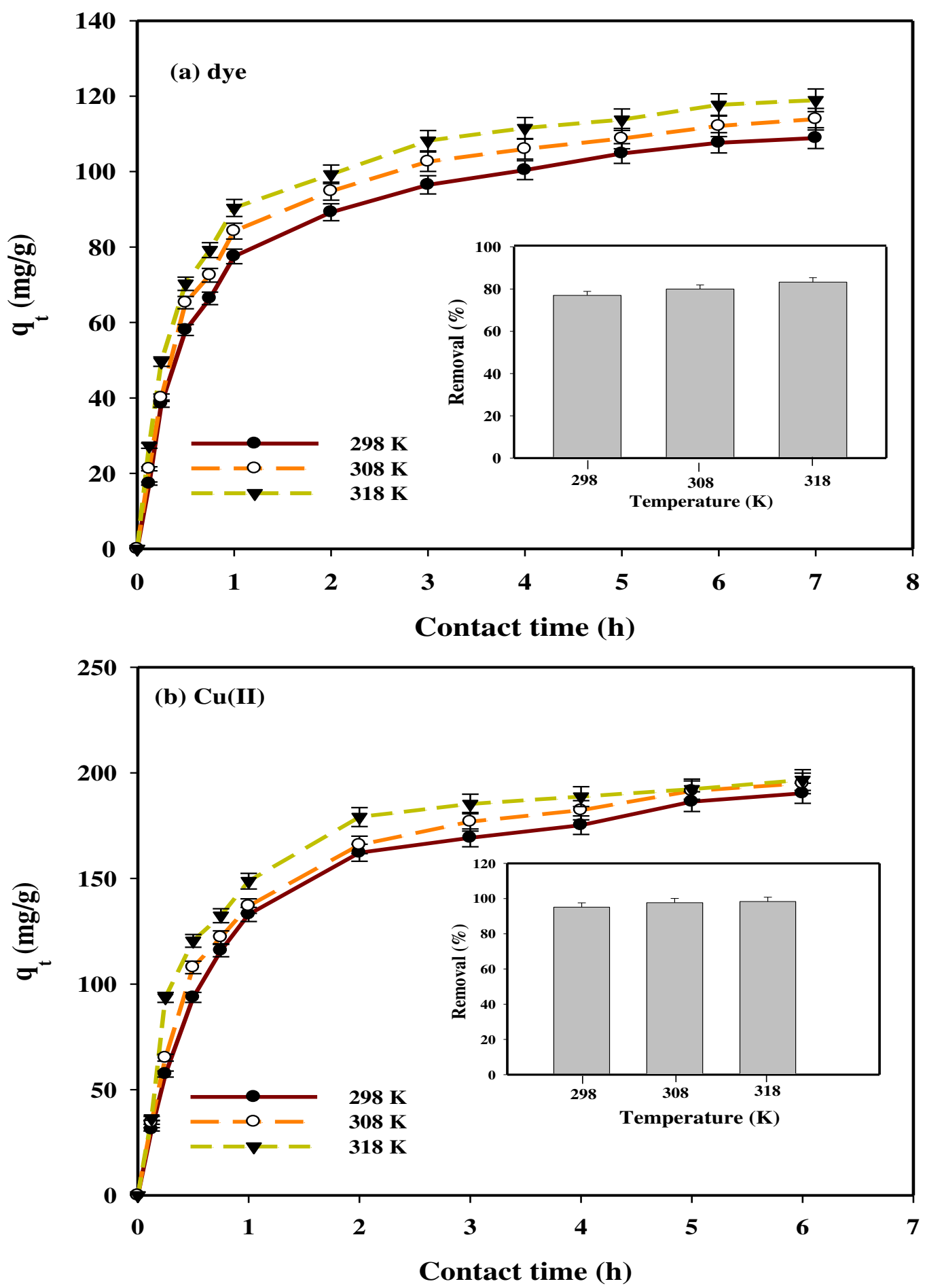

Figure (9):- Impact of temperature $(\mathrm{K})$ with contact time (h) onto the amount adsorbed (mg/g) and removal (\%) of the (a) basic blue 3 dye and (b) $\mathrm{Cu}$ (II) ions onto PVA-co$\mathrm{AAm} / \mathrm{TiO}_{2} / \mathrm{SiO}_{2}-30$ nanocomposite ( $\mathrm{pH} 11$ for the dye and $\mathrm{pH} 6$ for $\mathrm{Cu}$ (II) ions; contact time $7 \mathrm{~h}$ for the dye and $6 \mathrm{~h}$ for $\mathrm{Cu}$ (II); $0.3 \mathrm{~g}$ adsorbent dosage; initial concentration 150 $\mathrm{mg} / \mathrm{L}$ for the dye and $200 \mathrm{mg} / \mathrm{L}$ for $\mathrm{Cu}$ (II) ions; agitation speed $100 \mathrm{rpm}$ ). 


\subsubsection{Sorption isotherms.}

The sorption isotherm examines are significance in deciding the adsorption capacity of the PVA-co-AAm/ $/ \mathrm{TiO}_{2} / \mathrm{SiO}_{2}-30$ nanocomposite to identify the character of adsorption. Langmuir, Freundlich and Temkin isotherm models were used to fit the experimental data of the adsorption isotherm.

The Langmuir isotherm supposes that adsorption sites are energetically equivalent, indistinguishable and just monolayer adsorption takes place in the procedure. ${ }^{40}$ The Langmuir equation is expressed by equation (6):

$$
\frac{\mathrm{C}_{\mathrm{e}}}{\mathrm{q}_{\mathrm{e}}}=\frac{1}{\mathrm{q}_{\mathrm{m}} \mathrm{K}_{\mathrm{L}}}+\frac{\mathrm{C}_{\mathrm{e}}}{\mathrm{q}_{\mathrm{m}}}
$$

Where, $q_{e}(\mathrm{mg} / \mathrm{g})$ is the adsorption capacity at equilibrium, $q_{m}(\mathrm{mg} / \mathrm{g})$ is the maximum adsorption capacity, $C_{e}$ is the concentration of dye after adsorption $(\mathrm{mg} / \mathrm{L}) . K_{L}$ and $\mathrm{K}_{\mathrm{F}}$ are the Langmuir and Freundlich constant, respectively; $\mathrm{n}$ is related to the adsorption intensity. $K_{L}(\mathrm{~L} / \mathrm{g})$ and $q_{m}$ of Langmuir isotherm obtained by plotting the curve $C_{e} / q_{e}$ versus $C_{e}$.

Also, The favorability of PVA-co-AAm/ $/ \mathrm{TiO}_{2} / \mathrm{SiO}_{2}-30$ nanocomposite as an adsorbent for basic blue 3 dye and $\mathrm{Cu}$ (II) ions Langmuir adsorption constant $K_{L}$ and can be represented in terms of the Langmuir isotherm is $R_{L}$ which is a dimensionless separation. $R_{L}$ can be calculated using equation (7) that describes the adsorption process whether favorable or unfavorable. $R_{L}$ value is between $0-1$. If $R_{L}>1$ suggesting the adsorption is unfavorable, if $R_{L}=1$ suggesting the adsorption is linear, if $0<R_{L}<1$ suggesting the adsorption is favorable and if $R_{L}$ equals 0 , it represents irreversible adsorption

$$
R_{L}=\frac{1}{1+K_{L} C_{o}}
$$

The Freundlich model is an experimental equation utilized to express the multilayer adsorption on a heterogeneous surface ${ }^{41}$ and described by equation (8).

$$
\ln q_{e}=\ln K_{F}+\frac{1}{n} \ln C_{e}
$$

Meanwhile, $K_{F}$ is Freundlich isotherm constant $\left[\left(\mathrm{mg} \cdot \mathrm{g}^{-1}\right)\left(\mathrm{L} \cdot \mathrm{mg}^{-1}\right)^{1 / \mathrm{n}}\right](\mathrm{L} / \mathrm{g})$ obtained by plotting the curve $\ln q_{e}$ versus $\ln C_{e}$ and $n$ is (dimensionless) the heterogeneity factor associated with the adsorption intensity and adsorption capacity.

The Temkin isotherm model supposes that the adsorption heat of all molecules reduces linearly with the enhanced in coverage of the adsorbent surface, the adsorption is described by a homogeneous distribution up to the highest binding energy. The Temkin isotherm can be illustrated by Equation (9).

$$
q_{e}=\frac{\mathrm{RT}}{b_{T}} \ln K_{T}+\frac{R T}{b_{T}} \ln C_{e} \quad, \quad \mathrm{~B}=\frac{R T}{b_{T}}
$$

Where $\mathrm{K}_{\mathrm{T}}$ is the equilibrium-binding constant $\left(\mathrm{L}_{\mathrm{m}} \mathrm{mg}^{-1}\right)$ related to the maximum binding energy, $\mathrm{B}$ is corresponding to the adsorption heat, $\mathrm{T}$ is the temperature $(\mathrm{K})$ and $\mathrm{R}$ is the universal gas constant $(8.314 \mathrm{~J} / \mathrm{K} . \mathrm{mol})$.

Figure 10 shows the experimental Langmuir, Freundlich and Temkin isotherms plots for the removal of basic blue 3 dye or $\mathrm{Cu}$ (II) ions solution onto PVA-co$\mathrm{AAm} / \mathrm{TiO}_{2} / \mathrm{SiO}_{2}-30$ nanocomposite at temperature $298^{\circ} \mathrm{K}$. The resulted correlation coefficients $\mathrm{R}^{2}$ and the isotherm parameters $\left(\mathrm{K}_{\mathrm{L}}, \mathrm{K}_{\mathrm{F}}, \mathrm{K}_{\mathrm{T}}, \mathrm{q}_{\mathrm{m}}, \mathrm{n}\right)$ are scheduled in Table 2 . 
The Langmuir model has the much closed to unity $\mathrm{R}^{2}$ value than the other two isotherms. This corroborates the adsorption process is a monolayer onto PVA-co-AAm/ $/ \mathrm{TiO}_{2} / \mathrm{SiO}_{2}-30$ nanocomposite. The theoretical monolayer capacities of PVA-co-AAm/ $/ \mathrm{TiO}_{2} / \mathrm{SiO}_{2}-30$ nanocomposite $\left(\mathrm{q}_{\mathrm{m}, \mathrm{cal}}\right)$ for basic blue 3 dye and $\mathrm{Cu}$ (II) ions were also got closer to the experimentally resulted value (Table 2 ).

Table 2 presents the calculated $\mathrm{R}_{\mathrm{L}}$ values in the range of $0.0023-0.58111$ and 0.377 0.936 for dye and $\mathrm{Cu}(\mathrm{II})$ ions adsorption. $\mathrm{R}_{\mathrm{L}}$ is lower than $1\left(0<\mathrm{R}_{\mathrm{L}}<1\right)$ indicates that PVA-co-AAm $/ \mathrm{TiO}_{2} / \mathrm{SiO}_{2}-30$ nanocomposite is a good medium for the adsorption of chosen dye and $\mathrm{Cu}$ (II) ions. Also, the outcomes in Table 2 designate that the equilibrium results is not fitted to the Temkin or Freundlich isotherm model.

The adsorption capacity $\left(\mathrm{q}_{\mathrm{m}}\right)$ of basic blue 3 dye and $\mathrm{Cu}$ (II) ions onto PVA-co$\mathrm{AAm} / \mathrm{TiO}_{2} / \mathrm{SiO}_{2}-30$ nanocomposite were compared with the other adsorbents as represented in Table 3. It is apparent that PVA-co-AAm/ $/ \mathrm{TiO}_{2} / \mathrm{SiO}_{2}-30$ nanocomposite has a good adsorption capacity comparing with other adsorbents. Consequently, the prepared nanocomposite has a good potential for the adsorption of the dyes and heavy metal ions from aqueous solutions.

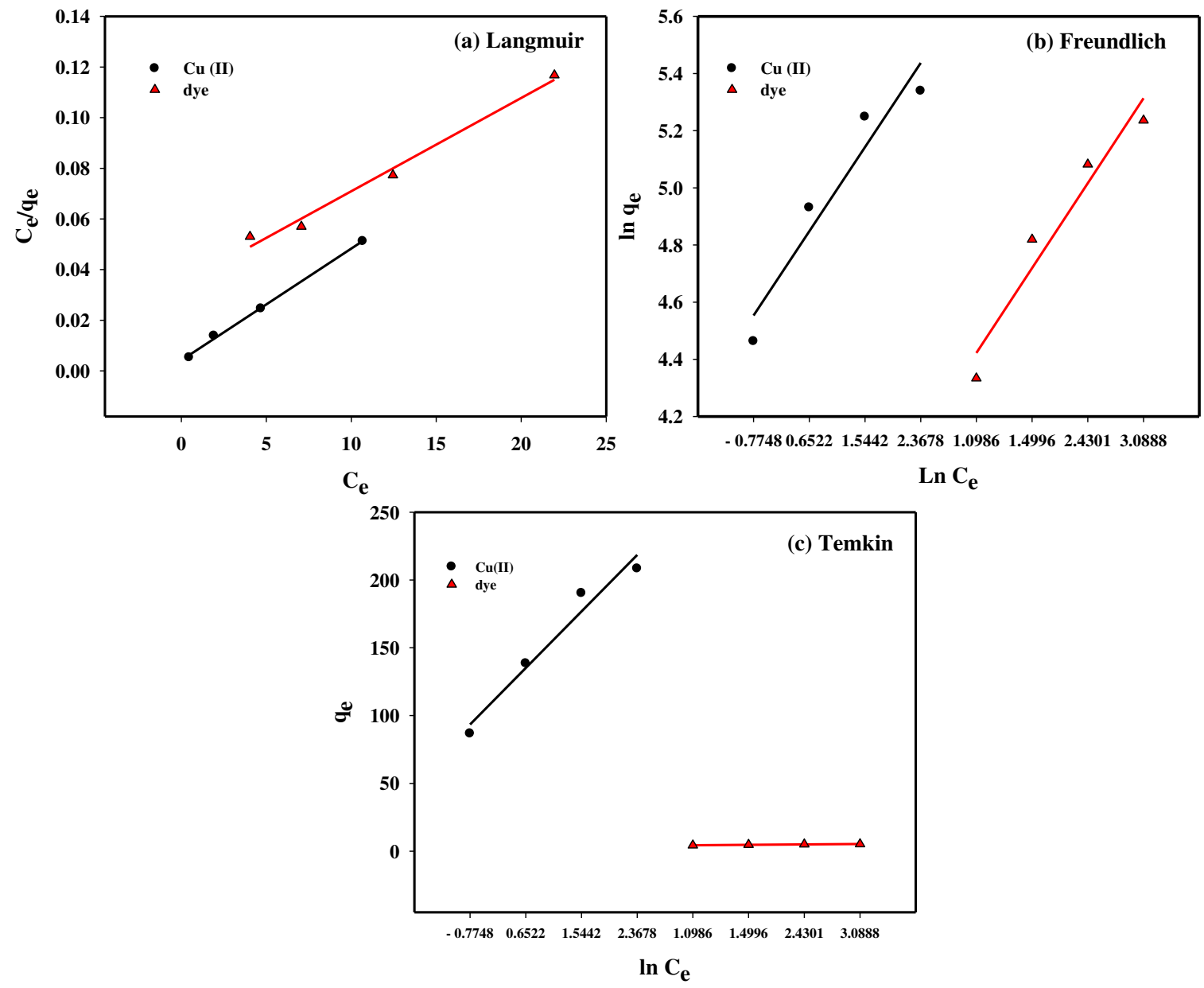

Figure (10):- (a) Langmuir, (b) Freundlich and (c) Temkin isotherm for adsorption of basic blue 3 dye and $\mathrm{Cu}$ (II) ions onto PVA-co- $\mathrm{AAm} / \mathrm{TiO}_{2} / \mathrm{SiO}_{2}-30$ nanocomposite. 
Table 2:- The Langmuir, Freundlish and Temkin isotherms and correlation coefficients parameters for adsorption of basic blue 3 dye and $\mathrm{Cu}$ (II) ions onto PVA-co$\mathrm{AAm} / \mathrm{TiO}_{2} / \mathrm{SiO}_{2}-30$ nanocomposites.

\begin{tabular}{|c|c|c|c|c|c|c|c|c|c|c|c|c|}
\hline \multirow[t]{2}{*}{ Adsorbate } & \multirow{2}{*}{$\begin{array}{l}q_{\mathrm{e}, \exp } \\
(\mathrm{mg} / \mathrm{g})\end{array}$} & \multicolumn{4}{|c|}{ Langmuir isotherm } & \multicolumn{3}{|c|}{ Freundlish isotherm } & \multicolumn{4}{|c|}{ Temkin isotherm } \\
\hline & & $\begin{array}{c}\mathbf{q}_{\mathrm{e}, \mathrm{cal}} \\
(\mathrm{mg} / \mathrm{g})\end{array}$ & $\begin{array}{c}\mathrm{K}_{\mathrm{L}}(\mathrm{L} / \\
\mathrm{mg}) \mathrm{x} \\
\mathbf{1 0}^{-3}\end{array}$ & $\mathbf{R}_{\mathbf{L}}$ & $\mathbf{R}^{2}$ & $\begin{array}{c}\mathrm{K}_{\mathrm{F}}\left(\mathrm{mg} \cdot \mathrm{g}^{-1}\right) \\
\left(\mathrm{L} \cdot \mathrm{mg}^{-1}\right)^{1 / \mathbf{n}}\end{array}$ & $\mathbf{n}$ & $\mathbf{R}^{2}$ & $\begin{array}{c}\mathbf{B} \\
\left(\mathbf{1 0}^{-5}\right. \\
\mathbf{L} \\
\left.\mathbf{m g}^{-1}\right) \\
\end{array}$ & $\mathbf{K}_{\mathbf{T}}$ & $\begin{array}{l}\mathbf{b}_{\mathrm{T}} \\
\mathrm{L} / \mathrm{g}\end{array}$ & $\mathbf{R}^{2}$ \\
\hline $\begin{array}{l}\text { Basic } \\
\text { blue } 3\end{array}$ & 123.86 & 171.37 & 1.711 & $\begin{array}{c}0.0023 \\
- \\
0.5811\end{array}$ & 0.9857 & 56.43 & 2.432 & 0.8752 & 4.11 & 18.27 & 60.28 & 0.8752 \\
\hline $\begin{array}{l}\mathrm{Cu}(\mathrm{II}) \\
\text { ions }\end{array}$ & 190.3 & 226.6 & 1.058 & $\begin{array}{c}0.377 \\
- \\
0.936\end{array}$ & 0.998 & 122.49 & 4.175 & 0.919 & 4.98 & 17.25 & 60.45 & 0.9393 \\
\hline
\end{tabular}


Table (3):- comparative study between PVA-co-AAm/ $/ \mathrm{TiO}_{2} / \mathrm{SiO}_{2}-30$ nanocomposite with other adsorbents in the literature used for wastewater treatment.

\begin{tabular}{|c|c|c|c|c|c|}
\hline Adsorbent & adsorbate & $\begin{array}{l}\text { Adsorptio } \\
\text { n capacity } \\
(\mathrm{mg} / \mathrm{g})\end{array}$ & $\begin{array}{l}\text { kinetic } \\
\text { model }\end{array}$ & $\begin{array}{l}\text { Isotherm } \\
\text { model }\end{array}$ & Ref. \\
\hline $\begin{array}{l}\text { polyaniline/ carboxymethyl } \\
\text { cellulose/ } \mathrm{TiO}_{2} \\
\text { nanocomposites }\end{array}$ & $\begin{array}{l}\text { Congo } \\
\text { Red dye }\end{array}$ & 94.28 & $\begin{array}{l}\text { Pseudo- } \\
\text { second } \\
\text { order } \\
\text { model } \\
\end{array}$ & $\begin{array}{l}\text { Langmuir } \\
\text { isotherm } \\
\text { model }\end{array}$ & 42 \\
\hline $\begin{array}{l}\text { Chitosan/tripolyphosphate/ } \\
\mathrm{TiO}_{2} \text { nanocomposite }\end{array}$ & $\begin{array}{l}\text { orange } 16 \\
\text { dye }\end{array}$ & 618.7 & $\begin{array}{l}\text { Pseudo- } \\
\text { second } \\
\text { order } \\
\text { model }\end{array}$ & $\begin{array}{l}\text { Freundlich } \\
\text { model }\end{array}$ & 43 \\
\hline $\begin{array}{l}\text { phosphorylated } \\
\text { polyhydroxyethyl } \\
\text { methacrylate hydrogel }\end{array}$ & $\begin{array}{l}\mathrm{Cu}(\mathrm{II}) \\
\text { ions }\end{array}$ & 66.3 & $\begin{array}{l}\text { Pseudo- } \\
\text { second } \\
\text { order } \\
\text { model }\end{array}$ & $\begin{array}{l}\text { Langmuir } \\
\text { isotherm } \\
\text { model }\end{array}$ & 44 \\
\hline $\begin{array}{l}\text { Carboxymethyl-chitosan / } \\
\text { bentonite composite }\end{array}$ & $\begin{array}{l}\mathrm{Cu}(\mathrm{II}) \\
\text { ions }\end{array}$ & 81.4 & $\begin{array}{l}\text { Pseudo- } \\
\text { second } \\
\text { order } \\
\text { model }\end{array}$ & $\begin{array}{l}\text { Langmuir } \\
\text { isotherm } \\
\text { model }\end{array}$ & 45 \\
\hline $\begin{array}{l}\text { hydroxyapatite/biochar } \\
\text { nanocomposites }\end{array}$ & $\begin{array}{l}\mathrm{Cu}(\mathrm{II}) \\
\text { ions }\end{array}$ & $\begin{array}{l}99.01 \\
\mathrm{mg} / \mathrm{g}\end{array}$ & $\begin{array}{l}\text { Pseudo- } \\
\text { second } \\
\text { order } \\
\text { model }\end{array}$ & $\begin{array}{l}\text { Langmuir } \\
\text { isotherm } \\
\text { model }\end{array}$ & 46 \\
\hline \multirow[t]{2}{*}{$\begin{array}{l}\mathrm{PVA}-\mathrm{co}-\mathrm{AAm} / \mathrm{TiO}_{2} / \mathrm{SiO}_{2}-30 \\
\text { nanocomposite }\end{array}$} & $\begin{array}{l}\mathrm{Cu}(\mathrm{II}) \\
\text { ions }\end{array}$ & 190.3 & $\begin{array}{l}\text { Pseudo } \\
\text { second } \\
\text { order }\end{array}$ & $\begin{array}{l}\text { Langmuir } \\
\text { isotherm } \\
\text { model }\end{array}$ & $\begin{array}{l}\text { This } \\
\text { study }\end{array}$ \\
\hline & $\begin{array}{l}\text { Basic blue } \\
3 \text { dye }\end{array}$ & 123.8 & $\begin{array}{l}\text { Pseudo } \\
\text { second } \\
\text { order }\end{array}$ & $\begin{array}{l}\text { Langmuir } \\
\text { isotherm } \\
\text { model }\end{array}$ & $\begin{array}{l}\text { This } \\
\text { study }\end{array}$ \\
\hline
\end{tabular}

\subsubsection{Sorption kinetics}

The studies of the adsorption kinetics play a critical function for estimating the optimal conditions for an adsorption process in order to evaluate the adsorbent features. This is because the adsorption capacity is an important parameter for determination the adsorbed amount of the pollutants (dye or metal ions) by the adsorbent. Thus, several kinetics adsorption models were modulated to assess the experimental data and to best fit the kinetics for the adsorption mechanism process of the basic blue 3 dye or $\mathrm{Cu}$ (II) on PVA-co-AAm/ $/ \mathrm{TiO}_{2} / \mathrm{SiO}_{2}-30$ nanocomposite. Among of them (i) the pseudo first order model as applied in Equation 10 (the most dependable kinetics equation appropriate merely for the quick initial phase), (ii) the pseudo second order model (for expecting the kinetic performance of chemical sorption as a rate controlling advance) expressed by Equation 11 and (iii) the intra-particle diffusion equation (supposes that the mass transfer resistance influence the binding of the contamination to the adsorbent surface) as expressed in Equation 12. 
The pseudo-first-order proposed by Lagergren and Svenska $1898{ }^{47}$ as presented by equation (10)

$$
\ln \left(q_{e}-q_{t}\right)=\ln q_{e 1, c a l}-K_{1} t
$$

The pseudo-second-order kinetics model ${ }^{48}$ is presented by equation (11):

$$
\frac{t}{q_{t}}=\frac{1}{k_{2} q_{e 2, c a l}^{2}}+\frac{t}{q_{e 2, c a l}}
$$

$\mathrm{q}_{\mathrm{e}}, \mathrm{q}_{\mathrm{e}, \mathrm{cal}}$ and $\mathrm{q}_{\mathrm{t}}$ are the experimental, calculated and the adsorbed amount of the dye or $\mathrm{Cu}$ (II) $(\mathrm{mg} / \mathrm{g})$ at time $\mathrm{t}(\mathrm{min})$, respectively. $\mathrm{K}_{1}\left(\mathrm{~min}^{-1}\right)$ and $\mathrm{K}_{2}\left(\mathrm{~g} \mathrm{mg}^{-1} \mathrm{~min}^{-1}\right)$ are the pseudo first order and the pseudo second order rate constants, respectively. The linear plots of the curve $\ln \left(q_{e}-q_{t}\right)$ versus time ( $\left.\mathrm{min}\right)$ were used to calculate the values of the rate constant $\left(K_{l}\right)$, meanwhile, $\left(t / q_{t}\right)$ versus time $(\mathrm{min})$ was used to calculate the values of the rate constant $\left(K_{2}\right)$.

The intra-particle diffusion equation

$$
q_{t}=k_{i d} t^{0.5}+C
$$

where $\mathrm{k}_{\text {id }}\left(\mathrm{mg} . \mathrm{g}^{-1} \cdot \mathrm{min}^{-0.5}\right)$ is the intra-particle diffusion rate constant.

The experimental results fitted to the kinetics models revealed above. The pseudo first order constants $\mathrm{k}_{1}, \mathrm{q}_{\mathrm{e} 1 \text {,cal }}$ and $\mathrm{R}^{2}$ for the studied basic blue 3 dye or $\mathrm{Cu}$ (II) ions adsorption onto PVA-co-AAm/ $/ \mathrm{TiO}_{2} / \mathrm{SiO}_{2}-30$ nanocomposite are represented in Figure 11 and Table 4. The theoretical $\mathrm{q}_{\mathrm{e}}$ quantity calculated from the first order kinetic model ( $\left.\mathrm{q}_{\mathrm{e} 1, \mathrm{cal}}\right)$ disagree with the practical quantity ( $\mathrm{q}_{\mathrm{e}, \mathrm{exp}}$ ), and the correlation coefficients was likewise established to be marginally lower. These outcomes represented that the pseudo first order kinetic model was not fitting for the adsorption of tested adsorbates.

As indicated by the outcomes recorded in Table 4 , the estimations of $\mathrm{R}^{2}$ for the pseudo second order kinetic model were a lot nearer to unity for the adsorbent PVA-co$\mathrm{AAm} / \mathrm{TiO}_{2} / \mathrm{SiO}_{2}-30$ nanocomposite. The intra-particle diffusion model represented a helpless fit to the practical data, meaning that the intra-particle diffusion was not the rate determining step in the adsorption. The adsorption capacities determined from the pseudo second order model $\mathrm{q}_{\mathrm{e} 2 \text {,cal }}$ were likewise near to those obtained by experiments $\left(\mathrm{q}_{\mathrm{e}, \exp }\right)$. The pseudo second order model is depends on the hypothesis that the rate-deciding step might be a chemical sorption including valence powers via exchange or sharing of electrons between the adsorbate and the adsorbent ${ }^{49,50}$. The $n$ and $K_{2}$ data determined from the pseudo second order kinetic model were higher for $\mathrm{Cu}$ (II)ions than basic blue 3 dye. Among the mentioned models, pseudo second order is suitable model for fitting the adsorption process. 

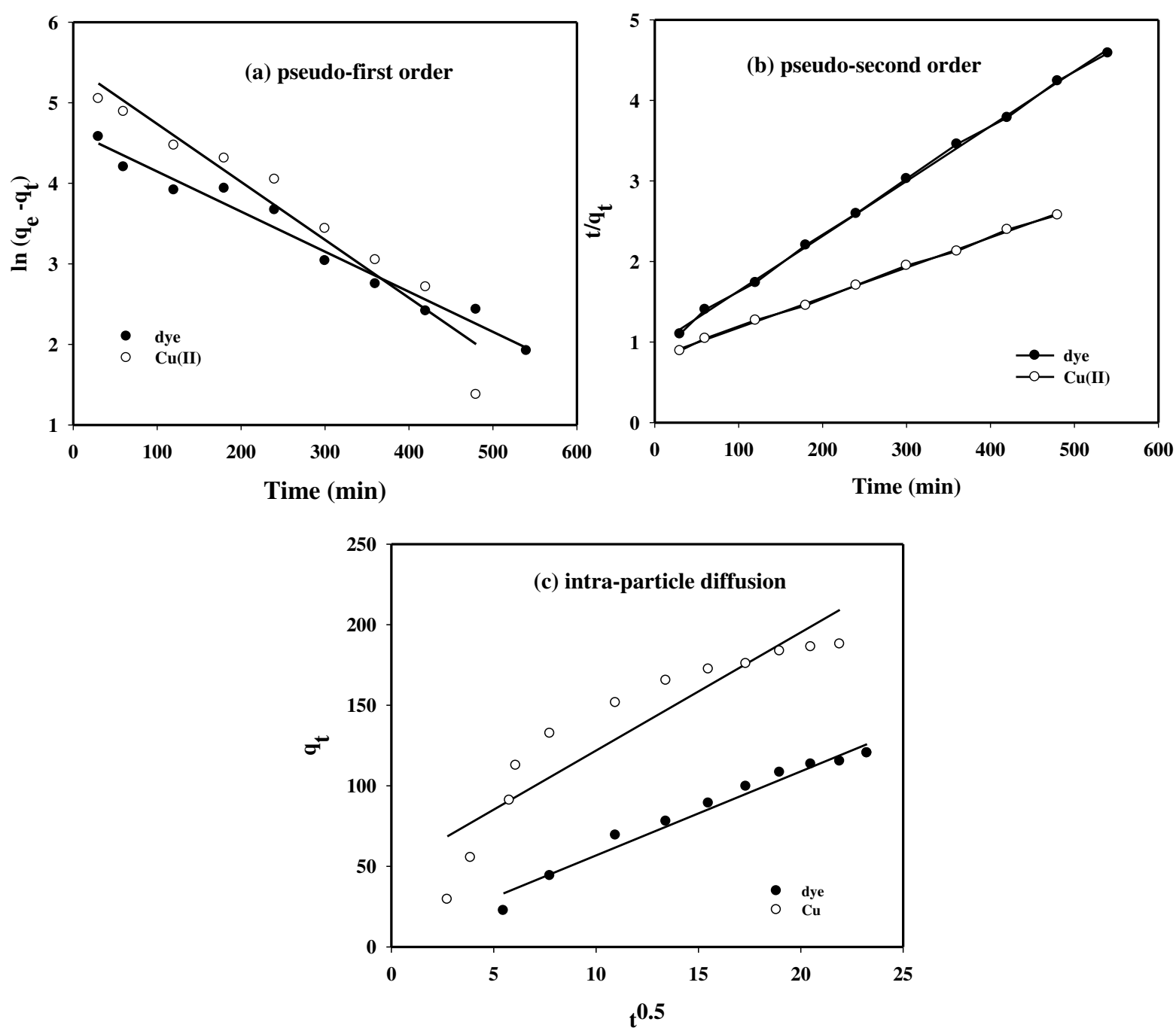

Figure (11):- plots of (a) pseudo first order, (b) pseudo second order and (c) intra-particle diffusion kinetic models applied for adsorption of basic blue 3 dye and $\mathrm{Cu}$ (II) ions onto PVA-co-AAm $/ \mathrm{TiO}_{2} / \mathrm{SiO}_{2}-30$ nanocomposite.

Table 4:- Kinetic parameters and correlation coefficients of for adsorption of basic blue 3 dye and $\mathrm{Cu}$ (II) ions onto PVA-co- $\mathrm{AAm} / \mathrm{TiO}_{2} / \mathrm{SiO}_{2}-30$ nanocomposite .

\begin{tabular}{|l|c|c|c|c|}
\hline adsorbate & qeeexp & Pseudo first order & Pseudo second order & Intra-particle diffusion \\
\hline
\end{tabular}




\begin{tabular}{|c|c|c|c|c|c|c|c|c|c|c|}
\hline & $(\mathrm{mg} / \mathrm{g})$ & & & & & & & \multicolumn{3}{|c|}{ model } \\
\hline & & $\begin{array}{c}K_{1} \\
\left(10^{-3}\right. \\
\left.\text { min }^{-1}\right)\end{array}$ & $\begin{array}{c}\mathbf{q} \text { Qe,cal } \\
(\mathbf{m g} / \mathbf{g})\end{array}$ & $\mathbf{R}^{2}$ & $\begin{array}{c}\mathrm{K}_{2} \\
\left(10^{-2} \mathbf{g} \cdot \mathrm{mg}^{-}\right. \\
\left.{ }^{1} \cdot \mathrm{min}^{-1}\right)\end{array}$ & $\begin{array}{c}\underset{(\mathbf{m g} / \mathbf{g})}{\mathbf{q}_{\mathrm{e}, \mathrm{cal}}} \\
\end{array}$ & $\mathbf{R}^{2}$ & $\underset{\mathbf{m i n}^{-0.5}\left(\mathbf{m g .} \mathbf{g}^{-1}\right.}{\mathbf{m i n}^{-0 .}}$ & $C_{i}$ & $\mathbf{R}^{2}$ \\
\hline Dye & 123.9 & 4.975 & 201.01 & 0.9716 & 4.878 & 146.7 & 0.9990 & 7.333 & 40.852 & 0.8527 \\
\hline $\mathrm{Cu}(\mathrm{II})$ & 190.3 & 7.194 & 233.9 & 0.9360 & 2.733 & 213.4 & 0.9986 & 5.213 & 4.649 & 0.9702 \\
\hline
\end{tabular}

\subsubsection{Adsorption thermodynamics.}

To describe the adsorption of basic blue 3 dye and $\mathrm{Cu}$ (II) ions onto PVA-co$\mathrm{AAm} / \mathrm{TiO}_{2} / \mathrm{SiO}_{2}-30$ nanocomposite anyway the procedure is spontaneous or nonspontaneous, the thermodynamic parameters, for example, standard enthalpy change $\left(\Delta \mathrm{H}^{0}\right)$, Gibbs free energy change $\left(\Delta \mathrm{G}^{0}\right)$ and standard entropy change $\left(\Delta \mathrm{S}^{0}\right)$ were calculated to recognize better the impact of the temperature on the adsorption process. The equilibrium constant $\mathrm{K}$ was used to calculate the Gibbs free energy $\left(\Delta \mathrm{G}^{0}\right)$ as in equation (13) where, $\mathrm{R}$ is gas constant $(8.314 \mathrm{~J} / \mathrm{mol} . \mathrm{K}), \mathrm{T}$ is the temperature in Kelvin $(\mathrm{K})$,

$$
\Delta G^{o}=-R T \ln k
$$

Additional thermodynamic parameters, such as enthalpy change $\left(\Delta \mathrm{H}^{\circ}\right)$ and entropy change $\left(\Delta S^{o}\right)$, were calculated from equation $(14)^{51}$ and illustrated in Figure 12:

$$
\ln k=\ln \left(\frac{q_{e}}{C_{e}}\right)=\frac{\Delta S^{o}}{R}-\frac{\Delta H^{o}}{R T}
$$

$\Delta \mathrm{H}^{\circ}$ and $\Delta \mathrm{S}^{\circ}$ were determined from (Figure 12) from the slope and intercept value of the linear plot of $\ln \left(q_{e} / C_{e}\right)$ versus $1 / T$. The obtained data are listed in Table 5. $\Delta \mathbf{G}^{\mathbf{0}}$ values established here are negative for adsorption of the dye and the $\mathrm{Cu}$ (II) onto the nanocomposite. This demonstrates that the adsorption procedure is spontaneous and thermodynamically practicable. Furthermore, the $\Delta \mathrm{G}^{0}$ values decreased as the temperature increased, demonstrating an increased tendency in the degree of practicability and spontaneity of uptake of the dye or metal ions onto PVA-co-AAm/ $/ \mathrm{TiO}_{2} / \mathrm{SiO}_{2}-30$ nanocomposite. The adsorption enthalpy change $\left(\Delta \mathrm{H}^{0}\right)$ was determined to be $35.97 \mathrm{~kJ} / \mathrm{mol}$ for $\mathrm{Cu}$ (II) and $31.13 \mathrm{~kJ} / \mathrm{mol}$ for the basic blue 3 dye adsorption onto PVA-co$\mathrm{AAm} / \mathrm{TiO}_{2} / \mathrm{SiO}_{2}-30$ nanocomposite, respectively. The positive change in enthalpy proposes that this adsorption is chemisorption. Additionally, positive $\Delta S^{0}$ indicates an irregular raise of the randomness at the nanocomposite-solution interface through adsorption. 


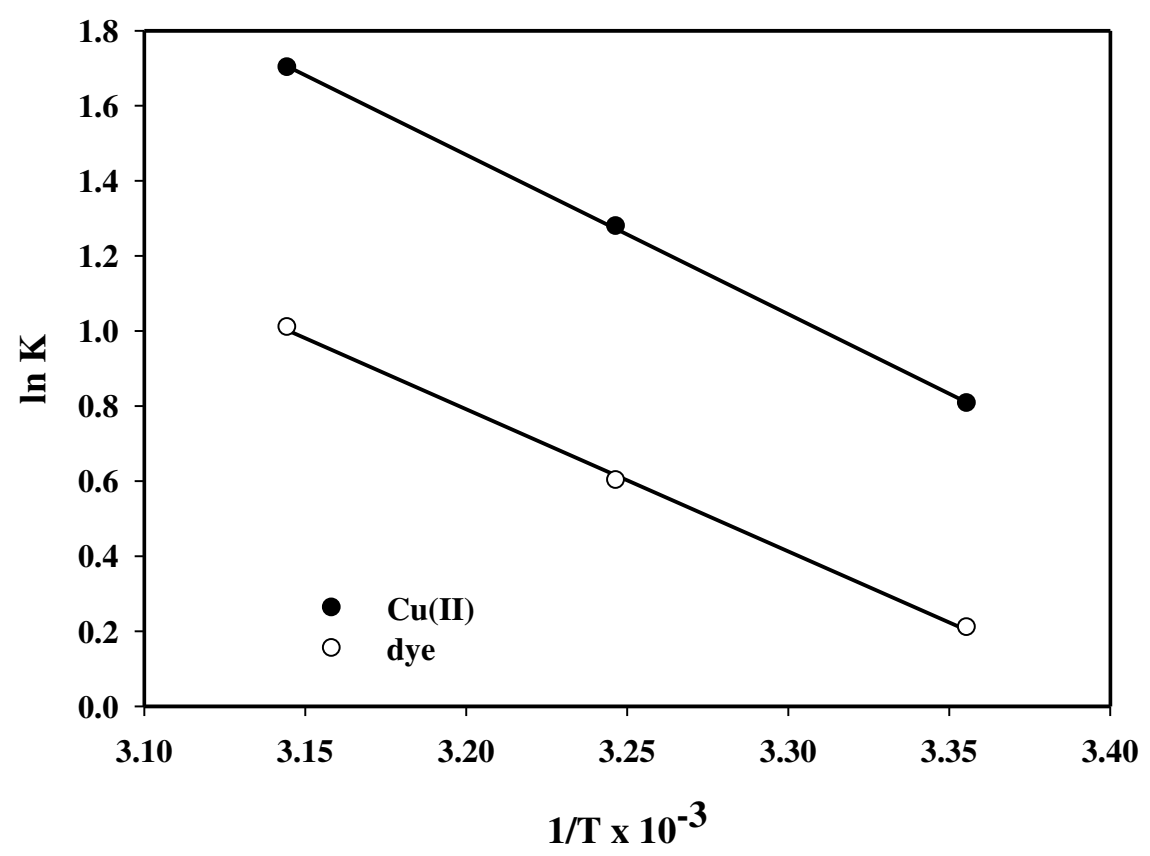

Figure (12):-Van't Hoff plots of the $\mathrm{Cu}$ (II) ions and basic blue 3 dye adsorption at different temperatures ( $50 \mathrm{ml}$ of initial concentration $150 \mathrm{mg} / \mathrm{l}$ for the dye and $200 \mathrm{mg} / \mathrm{l}$ for $\mathrm{Cu}$ (II) ions; $0.3 \mathrm{~g}$ adsorbent dosage, $\mathrm{pH} 6$ for $\mathrm{Cu}$ (II) and $\mathrm{pH} 11$ for the dye; contact time $6 \mathrm{~h}$ for $\mathrm{Cu}$ (II) and $7 \mathrm{~h}$ for the dye).

Table 5:- Thermodynamic parameters at different temperatures

\begin{tabular}{|c|c|c|c|c|c|}
\hline \multirow[t]{2}{*}{ adsorbate } & \multirow{2}{*}{$\begin{array}{c}\text { Standard enthalpy } \\
\Delta \mathrm{H}^{\mathrm{o}}\left(\mathrm{kJ} \cdot \mathrm{mol}^{-1}\right)\end{array}$} & \multirow{2}{*}{$\begin{array}{l}\text { Standard entropy } \\
\Delta \mathrm{S}^{\mathrm{o}}\left(\mathrm{J} \cdot \mathrm{mol}^{-1} \cdot \mathrm{K}^{-1}\right)\end{array}$} & \multicolumn{3}{|c|}{ Gibbs free energy $\Delta \mathrm{G}^{\mathrm{o}}\left(\mathrm{kJ} \cdot \mathrm{mol}^{-1}\right)$} \\
\hline & & & $298 \mathrm{~K}$ & $308 \mathrm{~K}$ & $318 \mathrm{~K}$ \\
\hline Basic blue 3 & 31.132 & 10.51 & -31.024 & -33.104 & -34.241 \\
\hline $\mathrm{Cu}$ (II) ion & 35.965 & 13.11 & -38.013 & -40.937 & -41.985 \\
\hline
\end{tabular}

\subsubsection{Reuse of adsorbents.}

The reuse of adsorbents after a particular procedure is perhaps the main significant properties for economic and environmental reasons. Thus, the desorption-adsorption series were carried out to examine the capability of PVA-co-AAm/ $/ \mathrm{TiO}_{2} / \mathrm{SiO}_{2}-30$ nanocomposite for application. In this work, ethanol and sodium hydroxide (alkaline environment $0.1 \mathrm{M}$ ) solution were utilized as desorption medium for basic blue 3 dye. Desorption of adsorbed $\mathrm{Cu}(\mathrm{II})$, was done utilizing nitric acid solution and the reusability was assessed four times as demonstrated in figure 13. It was established from this figure that adsorption of $\mathrm{Cu}$ (II) or basic blue 3 dye was very little influenced. In this manner, PVA-co-AAm/ $/ \mathrm{TiO}_{2} / \mathrm{SiO}_{2}-30$ nanocomposite can be utilized many times for water contamination remediation. 


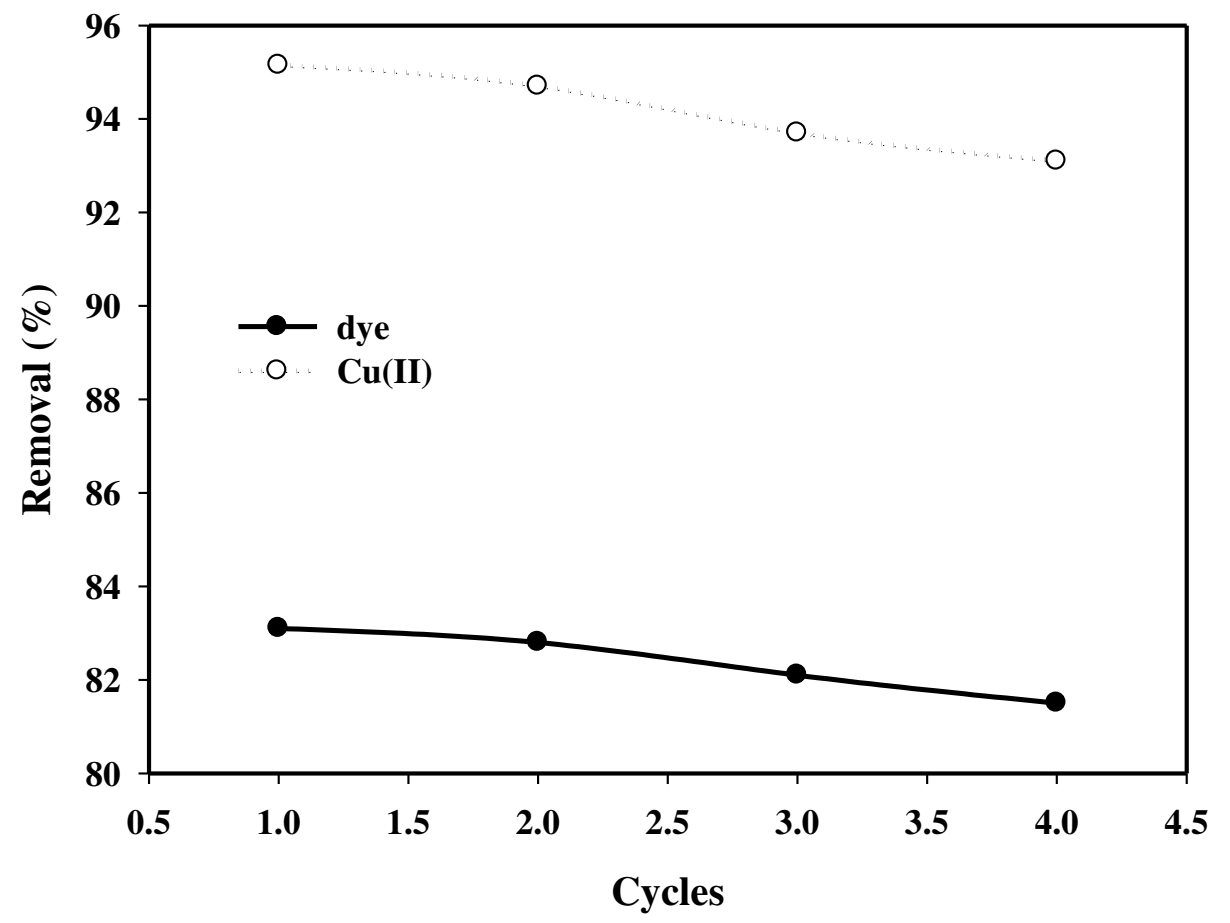

Figure 13: effect of cycle times on removal (\%) of basic blue 3 dye and $\mathrm{Cu}$ (II) onto PVAco-AAm $/ \mathrm{TiO}_{2} / \mathrm{SiO}_{2}-30$ nanocomposite

\section{Conclusion}

Novel PVA-co-AAm/ $/ \mathrm{TiO}_{2} / \mathrm{SiO}_{2}$ nanocomposites prepared by $\gamma$-irradiation polymerization crosslinking of PVA and AAm incorporated with $\mathrm{TiO}_{2} / \mathrm{SiO}_{2}$ nanoparticles. The highest and equilibrium swelling (\%) of the prepared nanocomposites was noticed at $30 \mathrm{kGy}$. The chemical structure of the prepared nanocomposites was an;lyzed by FT-IR, XRD, EDS, SEM, TEM and DLS. The adsorption capacity of PVA-co-AAm/TiO $/ \mathrm{SiO}_{2}$ nanocomposites towards basic blue 3 dye and $\mathrm{Cu}$ (II) ions was studied. The prepared nanocomposites at different doses showed high adsorption capacity 3 folds compared by PVA-co-AAm adsorbent. The PVA-co-AAm/ $/ \mathrm{TiO}_{2} / \mathrm{SiO}_{2}-30$ shows high swelling (\%) as well as high adsorption and removal $(\%)$ towards the tested dye and metal ions. The optimum adsorption capacity $(\mathrm{mg} / \mathrm{g}$ ) and removal (\%) of basic blue 3 dye or $\mathrm{Cu}(\mathrm{II})$ ions from their aqueous solutions onto PVA-co-AAm/ $\mathrm{TiO}_{2} / \mathrm{SiO}_{2}$ nanocomposites were dependent on irradiation of cross-linking, $\mathrm{pH}$, temperature, initial of dye or metal concentration, type of and contact time. The equilibrium adsorption for basic blue dye was about $123.9 \mathrm{mg} / \mathrm{g}$ with Removal of $82.6 \%$ at $7 \mathrm{~h}$ contact time, $\mathrm{pH} \mathrm{11}$, adsorbent dosage 0.3 and initial concentration $150 \mathrm{mg} / \mathrm{L}$. Also, The equilibrium adsorption for $\mathrm{Cu}(\mathrm{II})$ ions was about $190.3 \mathrm{mg} / \mathrm{g}$ with Removal of $95.1 \%$ at $6 \mathrm{~h}, \mathrm{pH}$ 6, adsorbent dosage $0.3 \mathrm{~g}$ and initial concentration $200 \mathrm{mg} / \mathrm{L}$. The adsorption kinetics suggested that the adsorption of each of the dye or $\mathrm{Cu}(\mathrm{II})$ ions on the nanocomposite best agree with the Pseudo second order model. The adsorption isotherm results confirmed that the adsorption were fitted to the Langmuir adsorption. The thermodynamic study confirmed that the chemi-sorption 
procedure was spontaneous and endothermic. Therefore, the radiation prepared PVA-co$\mathrm{AAm} / \mathrm{TiO}_{2} / \mathrm{SiO}_{2}$ nanocomposite could be applied as an efficient and novel adsorbent for elimination of dyes and metal cations from contaminated water with high adsorption capacity and convenient recovery.

\section{Ethical approval}

Not applicable.

\section{Consent to participate}

Not applicable.

\section{Consent to publish}

Not applicable. All authors approved for publication.

\section{Author's contributions}

Ahmed M.Elbarbary was responsible for the conception and design, testing, data acquisition, writing - review, and editing. Yasser H.Gad was responsible for analysis and data interpretation, writing - review, and editing manuscript. All authors read, revise, and approved the final manuscript.

\section{Funding}

Not applicable.

\section{Data availability statement}

The data that support the findings of this study are available from the corresponding author upon reasonable request.

\section{Conflict of interest}

The authors declare that they have no competing interests and non-financial competing interests.

\section{ORCHID}

Ahmed M. Elbarbary: https://orcid.org/0000-0001-5318-602X

Yasser H. Gad: https://orcid.org/0000-0002-6973-0701

\section{References}

${ }^{1}$ Vareda, J.P.; Valente, A.J.M.; Durães, L. Assessment of heavy metal pollution from anthropogenic activities and remediation strategies: A review.J. Environ. Manag.2019, 246, $101-118$.

${ }^{2}$ Ahmad, Z.; Gao, B.; Mosa, A.; Yu, H.; Yin, X.; Bashir, A.; Ghoveisi, H.; Wang, S. Removal of $\mathrm{Cu}(\mathrm{II}), \mathrm{Cd}(\mathrm{II})$ and $\mathrm{Pb}(\mathrm{II})$ ions from aqueous solutions by biochars derived from potassium-rich biomass. J. Clean. Prod.2018, 180, 437-449.

${ }^{3}$ Akar, S.T.; Akar, T.; Kaynak, Z.; Anilan, B.; Cabuk, A.; Tabak, Ö.; Demir, T.A.; Gedikbey, T. Removal of copper(II) ions from synthetic solution and real wastewater by 
the combined action of dried Trametesversicolor cells and montmorillonite. Hydrometallurgy 2009, 97, 98-104.

${ }^{4}$ Uddin, M. K. (2017). A review on the adsorption of heavy metals by clay minerals, with special focus on the past decade. Chemical Engineering Journal, 308, 438-462

${ }^{5}$ Basri, S. N., Zainuddin, N., Hashim, K., \&Yusof, N. A. (2016).Preparation and characterization of irradiated carboxymethyl sago starch-acid hydrogel and its application as metal scavenger in aqueous solution. Carbohydrate polymers, 138, 34-40.

${ }^{6}$ Khalaf MN (ed) (2016) Green polymers and environmental pollution control. CRC Press; Apple Academic Press Inc, Oakville, p 436.

${ }^{7}$ Tanan, W., \&Saengsuwan, S. (2020). A one-pot microwave-assisted synthesis of IPN hydrogels based on HEMA/AM/PVA blend for enhancing $\mathrm{Cu}$ (II) and $\mathrm{Pb}$ (II) ions removal. Journal of Environmental Chemical Engineering, 8(2), 103469.

${ }^{8} \mathrm{Fu}$, F., \& Wang, Q. (2011). Removal of heavy metal ions from wastewaters: a review. Journal of environmental management, 92(3), 407-418.

${ }^{9}$ Crini G, Torri G, Lichtfouse É, Kyzas GZ, Wilson LD, Morin-Crini N (2019) Cross-linked chitosan hydrogels for dye removal. In: Crini G, Lichtfouse É (eds) Chitin and chitosanapplications in food, agriculture, pharmacy, medicine and wastewater treatment, vol 35. Sustainable agriculture reviews. Springer, Basel.https ://doi. org/10.1007/978-3-030-16581 $-9 \_10$.

${ }^{10}$ V. Dulman, S.-M.Cucu-Man, I. Bunia and M. Dumitras: 'Batch fixed bed column studies on removal of Orange $\mathrm{G}$ acid dye by a weak base functionalized polymer', Desalination and Water Treatment, 2016, 57, 14708-14727.

${ }^{11}$ J. Jordan, K. I. Jacob, R. Tannenbaum, M. A. Sharaf and I. Jasiuk:Experimental trends in polymer nanocomposites - a review', Mater.Sci. Eng. A, 2005, 393, 1-11.

${ }^{12}$ G. Lofrano, M. Carotenuto, G. Libralato, R. F. Domingos, A. Markus,L. Dini, R. K. Gautam, D. Baldantoni, M. Rossi, S. K. Sharma, M. C.Chattopadhyaya, M. Giugni and S. Meric: 'Polymer functionalizednanocomposites for metals removal from water and wastewater: Anoverview', Water Res., 2016, 92, 22-37.

${ }^{13}$ Akbarnejad, S., Amooey, A. A., \&Ghasemi, S. (2019). High effective adsorption of acid fuchsin dye using magnetic biodegradable polymer-based nanocomposite from aqueous solutions. Microchemical Journal, 149, 103966.

${ }^{14}$ Sarkar, A. K., Saha, A., Panda, A. B., \& Pal, S. (2015). pH Triggered superior selective adsorption and separation of both cationic and anionic dyes and photocatalytic activity on a fully exfoliated titanate layer-natural polymer based nanocomposite. Chemical Communications, 51(89), 16057-16060.

${ }^{15}$ Gong, N., Liu, Y., \& Huang, R. (2018).Simultaneous adsorption of $\mathrm{Cu} 2+$ and Acid fuchsin (AF) from aqueous solutions by $\mathrm{CMC} /$ bentonite composite. International journal of biological macromolecules, 115, 580-589. 
${ }^{16}$ Tanzifi, M., Yaraki, M. T., Karami, M., Karimi, S., Kiadehi, A. D., Karimipour, K., \& Wang, S. (2018). Modelling of dye adsorption from aqueous solution on polyaniline/carboxymethyl cellulose/TiO2 nanocomposites. Journal of colloid and interface science, 519, 154-173.

${ }^{17}$ Binaeian, E., Zadvarzi, S. B., \& Yuan, D. (2020).Anionic dye uptake via composite using chitosan-polyacrylamide hydrogel as matrix containing $\mathrm{TiO} 2$ nanoparticles; comprehensive adsorption studies. International journal of biological macromolecules, 162, 150-162.

${ }^{18}$ Awwad, A., Amer, M., \& Al-aqarbeh, M. (2020). TiO2-kaolinite nanocomposite prepared from the Jordanian Kaolin clay: Adsorption and thermodynamics of $\mathrm{Pb}$ (II) and $\mathrm{Cd}$ (II) ions in aqueous solution. Chemistry International 6(4) (2020) 168-17.

${ }^{19}$ Rezakazemi, M., Sadrzadeh, M., Mohammadi, T., \& Matsuura, T. (2017). Methods for the preparation of organic-inorganic nanocomposite polymer electrolyte membranes for fuel cells. In Organic-inorganic composite polymer electrolyte membranes (pp. 311-325). Springer, Cham.

${ }^{20}$ El-Sayyad, G. S., AbdElkodous, M., El-Khawaga, A. M., Elsayed, M. A., El-Batal, A. I., \& Gobara, M. (2020). Merits of photocatalytic and antimicrobial applications of gammairradiated $\mathrm{Co}$ x Ni 1- x Fe2O4/SiO2/TiO2; x= 0.9 nanocomposite for pyridine removal and pathogenic bacteria/fungi disinfection: implication for wastewater treatment. $R S C$ Advances, 10(9), 5241-5259.

${ }^{21}$ Zhu, C. H., Hai, Z. B., Cui, C. H., Li, H. H., Chen, J. F., \& Yu, S. H. (2012). In situ controlled synthesis of thermosensitive poly (N-isopropylacrylamide)/Au nanocomposite hydrogels by gamma radiation for catalytic application. Small, 8(6), 930-936.

${ }^{22}$ Hassan, D., \&Hashim, A. (2018).Preparation and Studying the Structural and Optical Properties of (Poly-Methyl Methacrylate-Lead Oxide) Nanocomposites for Bioenvironmental Applications. Journal of Bionanoscience, 12(3), 346-349.

${ }^{23}$ Elbarbary, A. M., Ibrahim, I. A., Shafik, H. M., \& Othman, S. H. (2017). Magnetic 99mTc-core-shell of polyethylene glycol/polyhydroxyethyl methacrylate based on Fe3O4 nanoparticles: Radiation synthesis, characterization and biodistribution study in tumor bearing mice. Advanced Powder Technology, 28(8), 1898-1910.

${ }^{24}$ Elbarbary, A. M., \& El-Sawy, N. M. (2017).Radiation synthesis and characterization of polyvinyl alcohol/chitosan/silver nanocomposite membranes: antimicrobial and blood compatibility studies. Polymer Bulletin, 74(1), 195-212.

${ }^{25}$ Nagi M. El-Shafai, Rencai Ji, Mahmoud Abdelfatah, Mohamed A. Hamada, A.W. Kandeal, Ibrahim M. El-Mehasseb, Abdelhamid El-Shaer, Meng An, Mohamed S. Ramadan, Swellam W. Sharshir, Walid Ismail, (2021). Investigation of a novel (GO@ $\mathrm{CuO} . \gamma$-Al2O3) hybrid nanocomposite for solar energy applications. Journal of Alloys and Compounds, 856, 157463.

${ }^{26}$ Singh, K., Barai, D. P., Chawhan, S. S., Bhanvase, B. A., \& Saharan, V. K. (2021). Synthesis, characterization and heat transfer study of reduced graphene oxide-A12O3 
nanocomposite based nanofluids: Investigation on thermal conductivity and rheology. Materials Today Communications, 26, 101986.

${ }^{27}$ El-Arnaouty M.B., Abdel Ghaffar A. M. , Abdel Baky A. A., Shama S. A., (2017), J. Vinyl\& Additive, 25, S1, E35-E43.

${ }^{28}$ Gaaz, T. S., Sulong, A. B., Akhtar, M. N., Kadhum, A. A. H., Mohamad, A. B., \& AlAmiery, A. A. (2015). Properties and applications of polyvinyl alcohol, halloysite nanotubes and their nanocomposites. Molecules, 20(12), 22833-22847.

${ }^{29}$ Marin, E., Rojas, J., \&Ciro, Y. (2014).A review of polyvinyl alcohol derivatives: Promising materials for pharmaceutical and biomedical applications. African Journal of Pharmacy and Pharmacology, 8(24), 674-684.

${ }^{30}$ Rabiee, A. (2010). Acrylamide-based anionic polyelectrolytes and their applications: A survey. Journal of Vinyl and Additive Technology, 16(2), 111-119.

${ }^{31}$ M. Hdidar, S. Chouikhi, A. Fattoum, M. Arous a, A. Kallel, " Multifunction applications of TiO2/poly(vinyl alcohol) nanocomposites for Laser attenuation applications " J. Alloy. Comp. 750 (2018) 375e383.

${ }^{32}$ J.B. Zhong, Y. Lu, W.D. Jiang, Q.M. Meng, X.Y. He, J.Z. Li, Y.Q. Chen, " Characterization and photocatalytic property of $\mathrm{Pd} / \mathrm{TiO} 2$ with the oxidation of gaseous benzene" J. Hazard Mater. 168 (2009) 1632-1635.

${ }^{33}$ W. Zhang, Q. Deng, Q. He, J. Song, S. Zhang, H. Wang, J. Zhou, H. Zhang, A facile synthesis of core-shell/bead-like poly (vinyl alcohol)/alginate@PAM with good adsorption capacity, high adaptability and stability towards $\mathrm{Cu}$ (II) removal, Chem. Eng. J. 351 (2018) $462-472$.

${ }^{34}$ E. Sonker, R. Tiwari, P. Adhikary, K. Kumar, S. Krishnamoorthi, Preparation of ultrahigh-molecular-weight polyacrylamide by vertical solution polymerization technique, Polym. Eng. Sci. 59 (2019) 1175-1181.

${ }^{35}$ E. Sonker, R. Tiwari, P. Adhikary, K. Kumar, S. Krishnamoorthi, Preparation of ultrahigh-molecular-weight polyacrylamide by vertical solution polymerization technique, Polym. Eng. Sci. 59 (2019) 1175-1181.

${ }^{36}$ Pourjafar, S., Rahimpour, A., \&Jahanshahi, M. (2012). Synthesis and characterization of PVA/PES thin film composite nanofiltration membrane modified with $\mathrm{TiO} 2$ nanoparticles for better performance and surface properties. Journal of Industrial and Engineering Chemistry, 18(4), 1398-1405.

37 KheamrutaiThamaphat, PichetLimsuwan and BoonlaerNgotawornchai, Phase Characterization of TiO2 Powder by XRD and TEM, Kasetsart J. (Nat. Sci.) 42 : 357 - 361 (2008)

${ }^{38}$ Cao, X., Ma, J., Shi, X., \&Ren, Z. (2006).Effect of TiO2 nanoparticle size on the performance of PVDF membrane. Applied Surface Science, 253(4), 2003-2010. 
${ }^{39}$ Pakdel, P. M., \&Peighambardoust, S. J. (2018). Review on recent progress in chitosanbased hydrogels for wastewater treatment application. Carbohydrate polymers, 201, 264279.

${ }^{40}$ I. Langmuir, "THE ADSORPTION OF GASES ON PLANE SURFACES OF GLASS, MICA AND PLATINUM” J. Am. Chem. Soc., 1918, 40, 1361-1403.

${ }^{41} \mathrm{H}$. Freundlich, "Of the adsorption of gases. Section II. Kinetics and energetics of gas adsorption.Introductory paper to section II” Trans. Faraday Soc., 1932, 28, 195-201.

${ }^{42}$ Tanzifi, M., Yaraki, M. T., Karami, M., Karimi, S., Kiadehi, A. D., Karimipour, K., \& Wang, S. (2018). Modelling of dye adsorption from aqueous solution on polyaniline/carboxymethyl cellulose/TiO2 nanocomposites. Journal of colloid and interface science, 519, 154-173.

${ }^{43}$ Abdulhameed, A. S., Mohammad, A. T., \&Jawad, A. H. (2019). Application of response surface methodology for enhanced synthesis of chitosan tripolyphosphate/TiO2 nanocomposite and adsorption of reactive orange 16 dye. Journal of Cleaner Production, 232, 43-56.

${ }^{44}$ Elbarbary, A. M., \& Ghobashy, M. M. (2017).Phosphorylation of chitosan/HEMA interpenetrating polymer network prepared by $\gamma$-radiation for metal ions removal from aqueous solutions. Carbohydrate polymers, 162, 16-27.

${ }^{45}$ Gong, N., Liu, Y., \& Huang, R. (2018).Simultaneous adsorption of $\mathrm{Cu} 2+$ and Acid fuchsin (AF) from aqueous solutions by $\mathrm{CMC} /$ bentonite composite. International journal of biological macromolecules, 115, 580-589.

${ }^{46}$ Jung, K. W., Lee, S. Y., Choi, J. W., \& Lee, Y. J. (2019). A facile one-pot hydrothermal synthesis of hydroxyapatite/biocharnanocomposites: adsorption behavior and mechanisms for the removal of copper (II) from aqueous media. Chemical Engineering Journal, 369, 529-541.

${ }^{47}$ Lagergren S, Svenska BK (1898) On the theory of socalled adsorption of dissolved substances, R. Swed.Acad. Sci. Doc. Band, 24 1-39.

${ }^{48}$ Ho YS, (2004) Citation Review of Lagergren Kinetic Rate Equation on Adsorption Reactions, Scientometrics, 59, 171-177.

${ }^{49}$ A. Masoumi, K. Hemmati and M. Ghaemy, "Structural modification of acrylonitrilebutadiene-styrene waste as an efficient nanoadsorbent for removal of metal ions from water: isotherm, kinetic and thermodynamic study", RSC Adv., 2015, 5, 1735-1744.

${ }^{50}$ G. Bayramoglu, B. Altintas and M. Y. Arica, "Adsorption kinetics and thermodynamic parameters of cationic dyes from aqueous solutions by using a new strong cation-exchange resin", Chem. Eng. J., 2009, 152, 339-346. 
${ }^{51}$ Gobi, K., M. Mashitah, and V. Vadivelu, Adsorptive removal of methylene blue using novel adsorbent from palm oil mill effluent waste activated sludge: equilibrium, thermodynamics and kinetic studies. Chemical engineering journal, 2011. 171(3): p. 12461252 . 
Figures

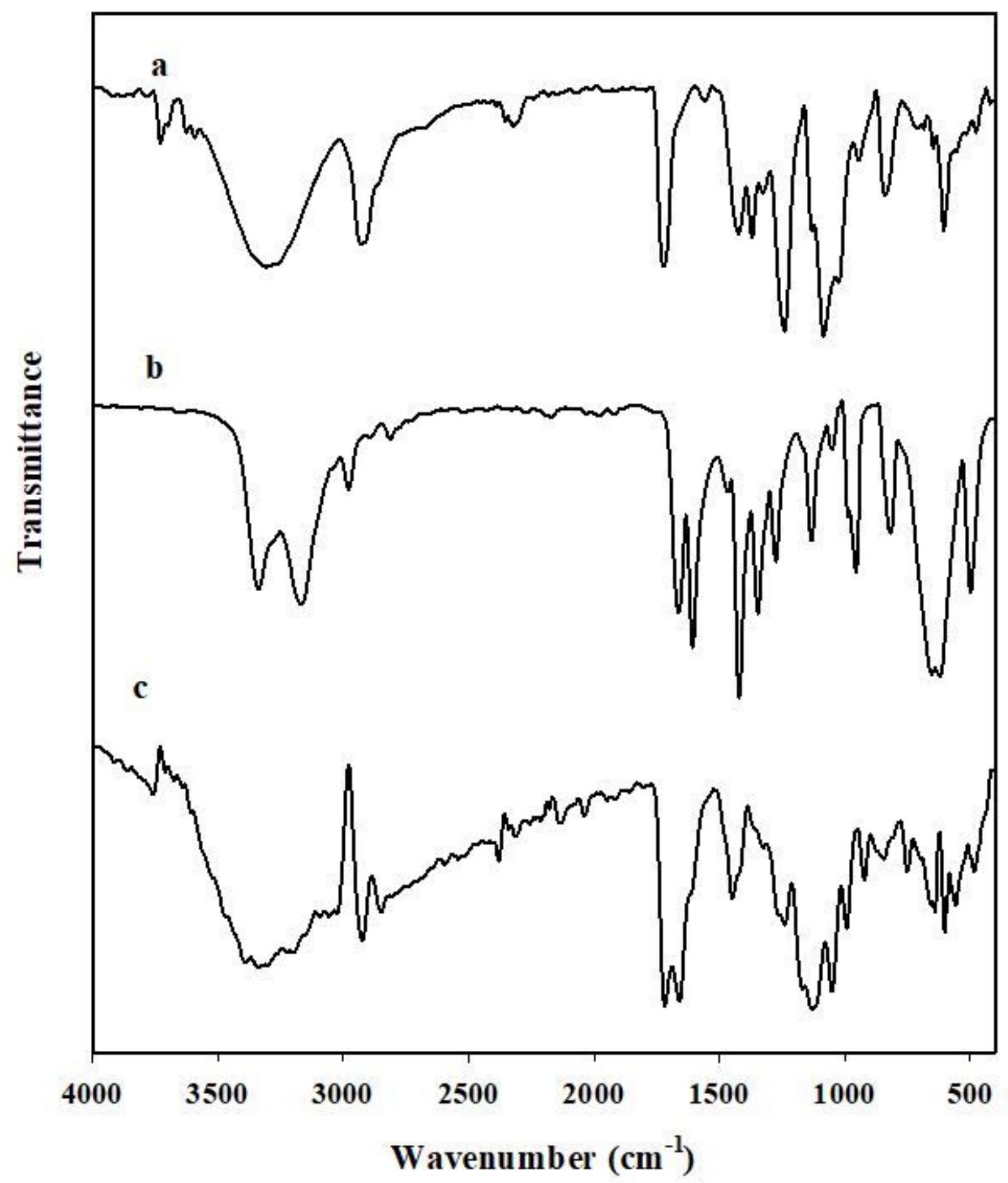

Figure 1

FTIR spectra of (a) PVA, (b) AAm and (c) PVA-co-AAm/TiO2/SiO2 nanocomposite. 


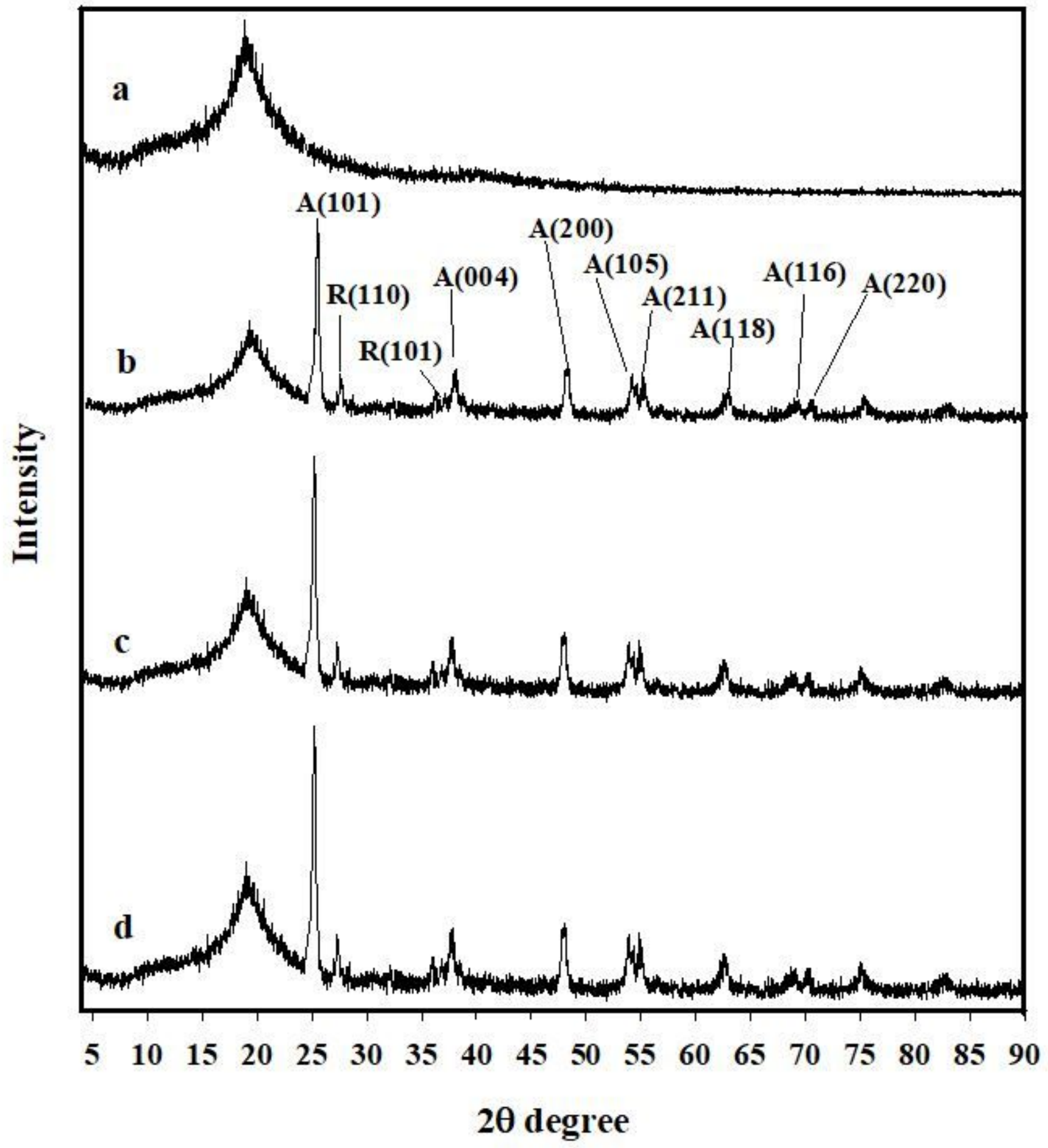

Figure 2

XRD curves of (a) PVA-co-AAm, (b) PVA-co-AAm/TiO2/SiO2-10 (c) PVA-co-AAm/TiO2/SiO2-30 and (d) PVA-co-AAm/TiO2/SiO2-50 nanocomposites. 
(a)

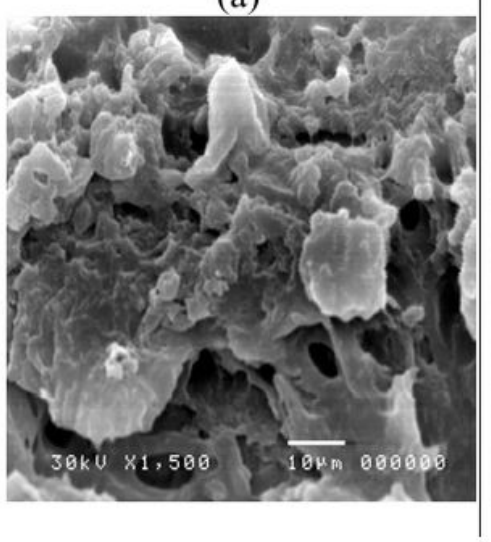

(b)

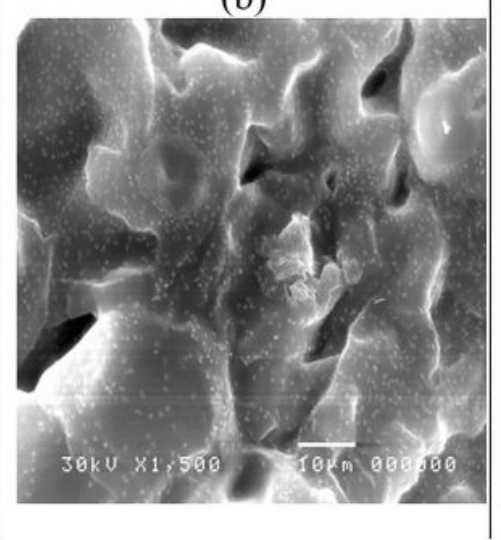

(c)

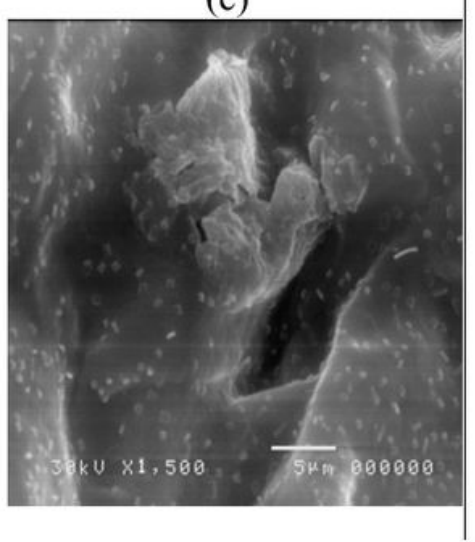

(d)

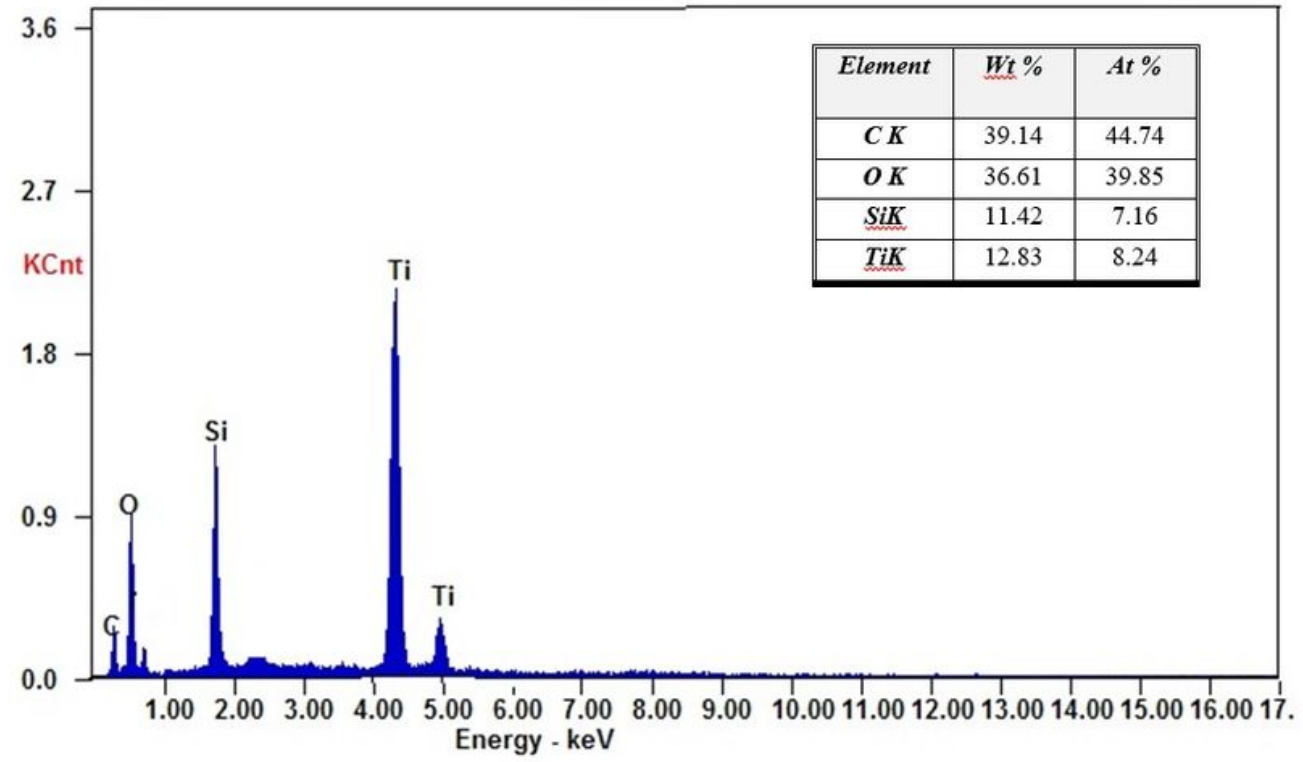

\section{Figure 4}

SEM micrographs of(a) PVA-co-AAm/TiO2/SiO2-10 (b) PVA-co-AAm/TiO2/SiO2-30 and (c) PVA-coAAm/TiO2/SiO2-50.(d) SEM/EDX spectrum of PVA-co-AAm/TiO2/SiO2-30 nanocomposite. 

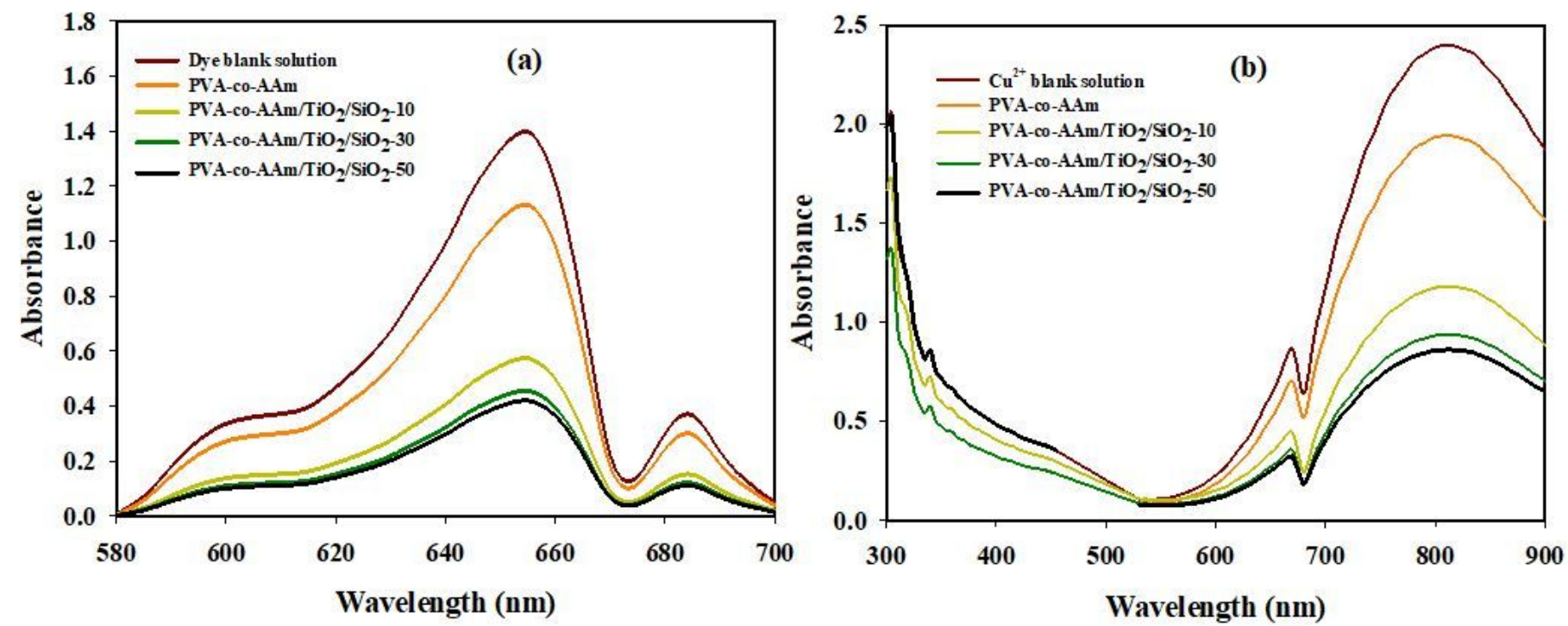

Figure 5

UV absorption spectra of (a) basic blue 3 dye and (b) Cu (II) ions by the effect of the prepared PVA-coAAm and PVA-co-AAm/TiO2/SiO2 nanocomposites. 

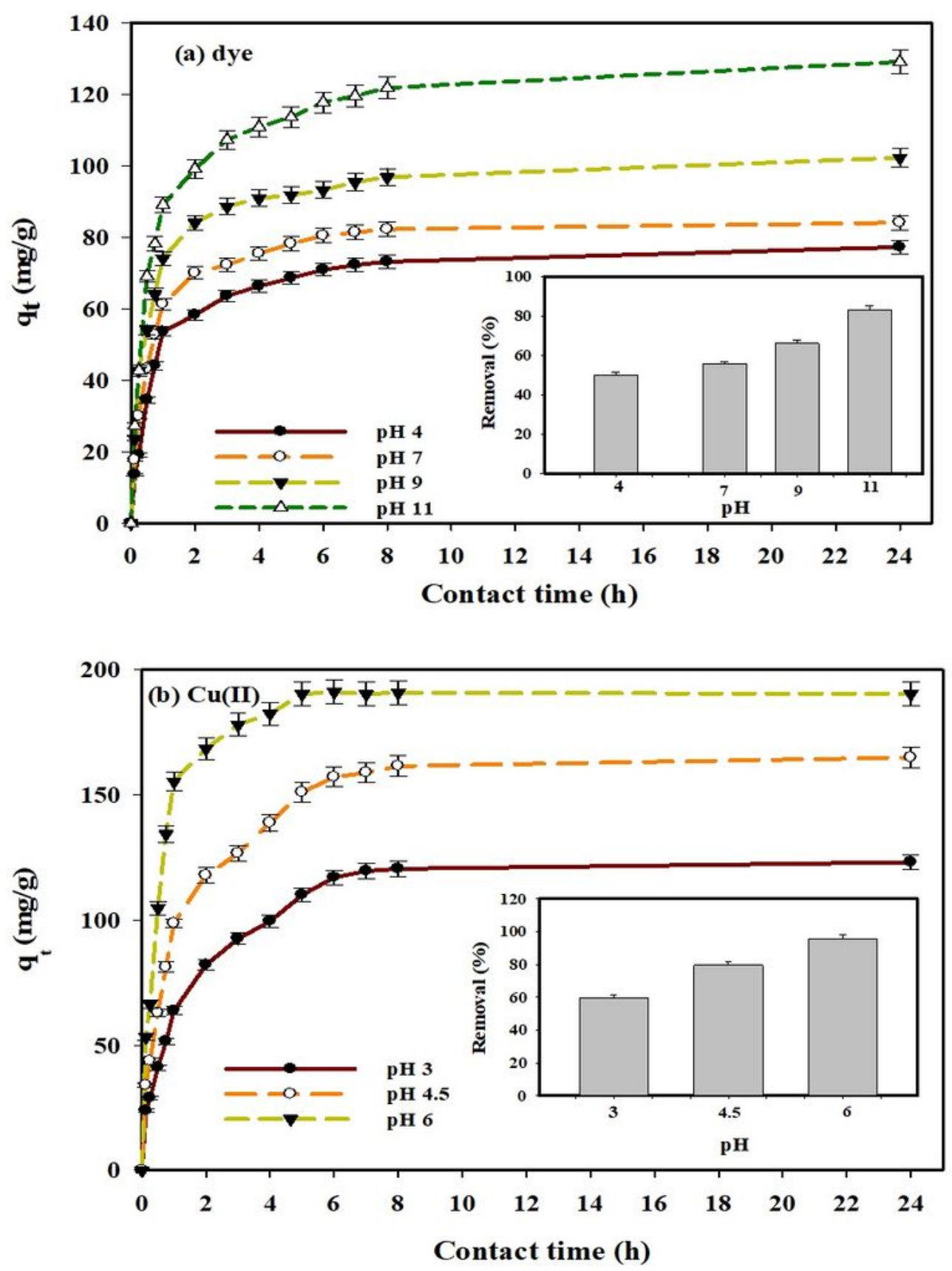

Figure 6

Effect of $\mathrm{pH}$ and contact time (h) on the amount adsorbed (qt) $(\mathrm{mg} / \mathrm{g}$ ) and removal (\%) of (a) basic blue 3 dye and (b) $\mathrm{Cu}$ (II) ions onto PVA-co-AAm/TiO2/SiO2 nanocomposite (initial concentration $150 \mathrm{mg} / \mathrm{L}$ for the dye and $200 \mathrm{mg} / \mathrm{L}$ for $\mathrm{Cu}$ (II) ions; adsorbent dosage $0.3 \mathrm{~g}$; temperature $298 \mathrm{~K}$; agitation speed 100 rpm). 

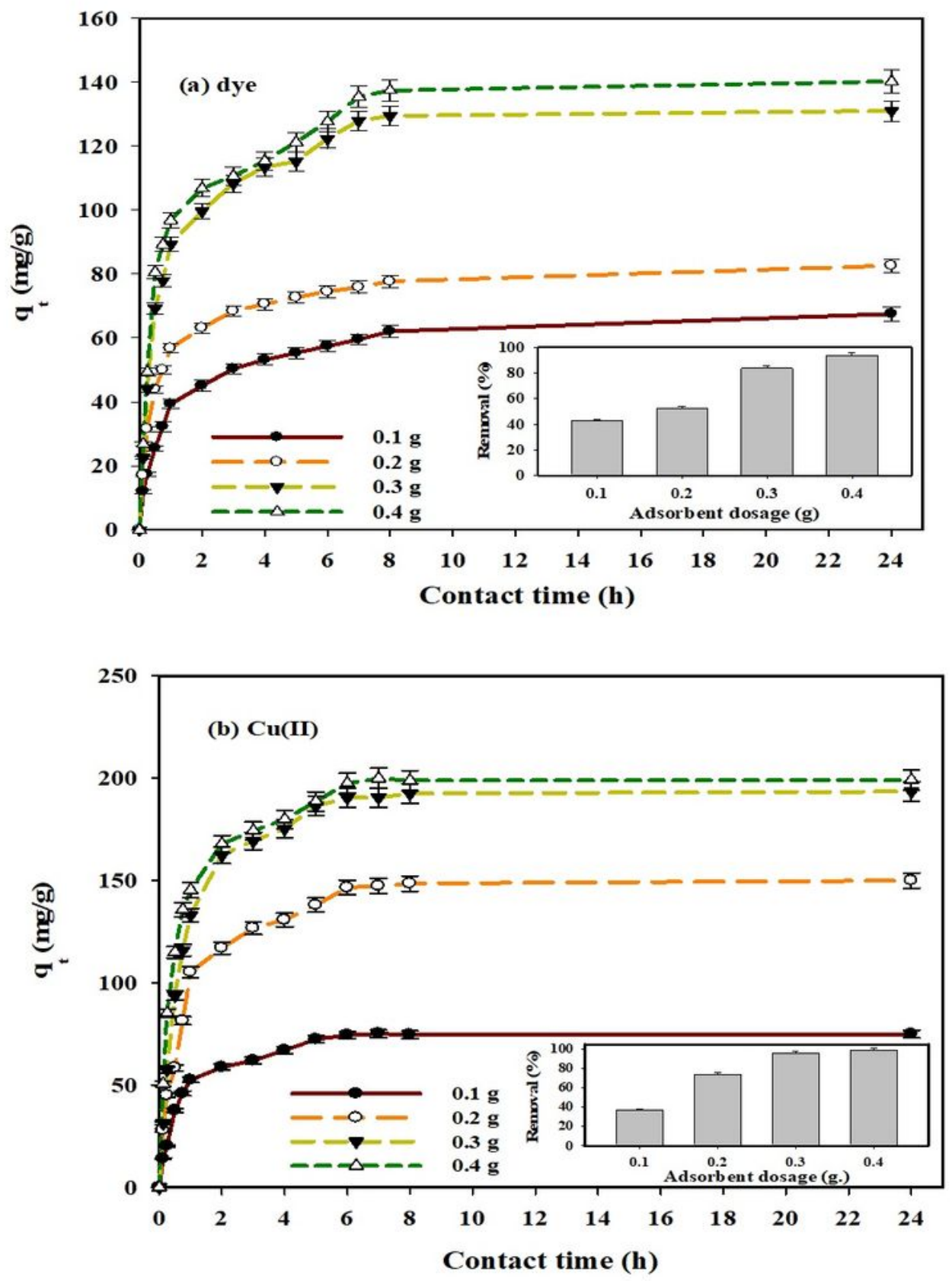

Figure 7

Effect of adsorbent dosages and contact time (h) on the amount adsorbed $(\mathrm{mg} / \mathrm{g})$ of the (a) basic blue 3 dye and (b) $\mathrm{Cu}$ (II) ions onto the PVA-co-AAm/TiO2/SiO2-30 nanocomposite (pH 11 for the dye and pH 6 for $\mathrm{Cu}$ (II); initial concentration $150 \mathrm{mg} / \mathrm{L}$ for the dye and $200 \mathrm{mg} / \mathrm{L}$ for Cu (II) ions; temperature $298 \mathrm{~K}$; agitation speed $100 \mathrm{rpm})$. 

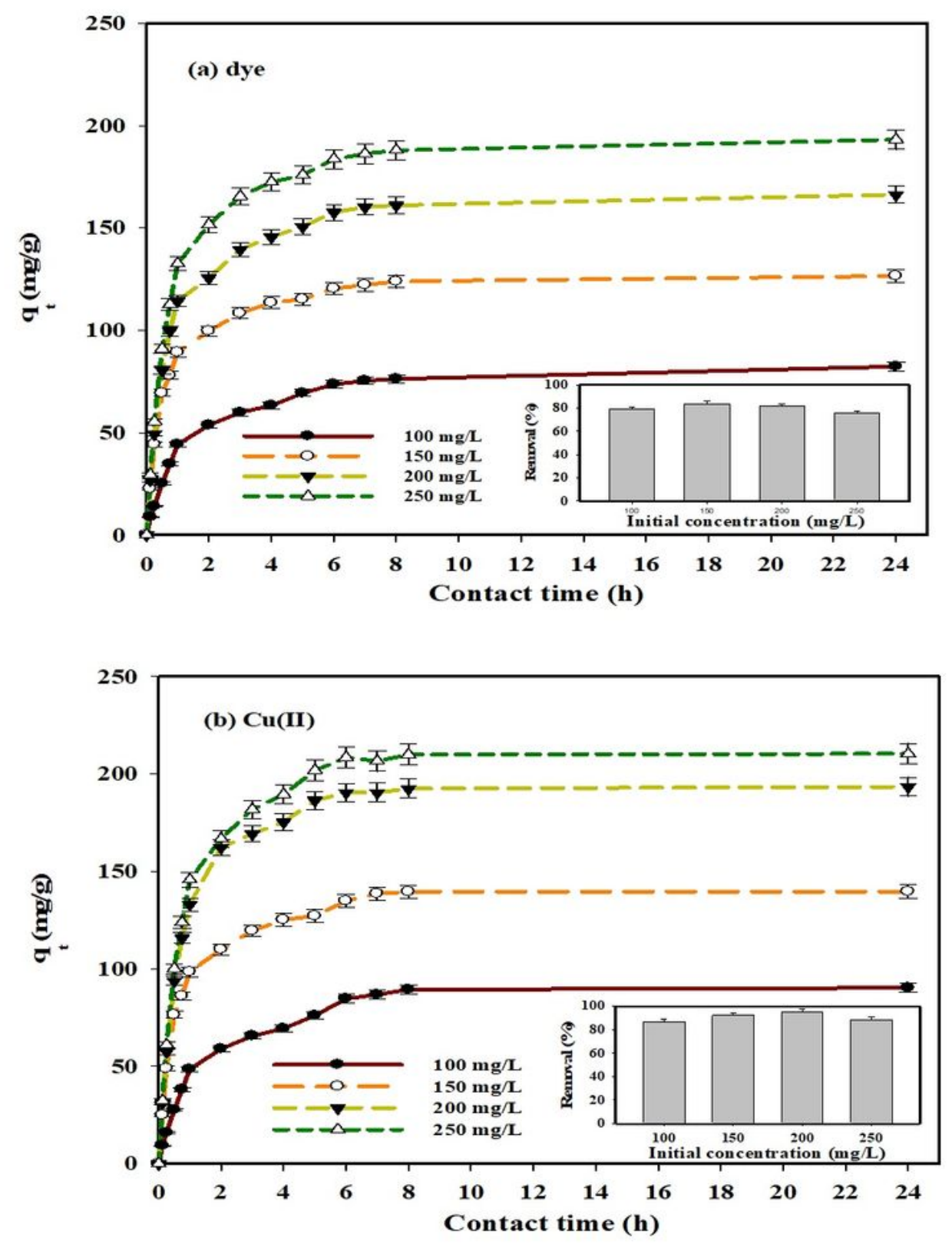

\section{Figure 8}

Impact of initial concentration $(\mathrm{mg} / \mathrm{l})$ with contact time $(\mathrm{h})$ onto the amount adsorbed $(\mathrm{mg} / \mathrm{g})$ and removal (\%) of the (a) basic blue 3 dye and (b) $\mathrm{Cu}$ (II) ions onto the PVA-co-AAm/TiO2/SiO2-30 nanocomposite ( $\mathrm{pH} 11$ for the dye and $\mathrm{pH} 6$ for $\mathrm{Cu}$ (II), $0.3 \mathrm{~g}$ adsorbent dosage. temperature $298 \mathrm{~K}$; agitation speed $100 \mathrm{rpm}$ ). 

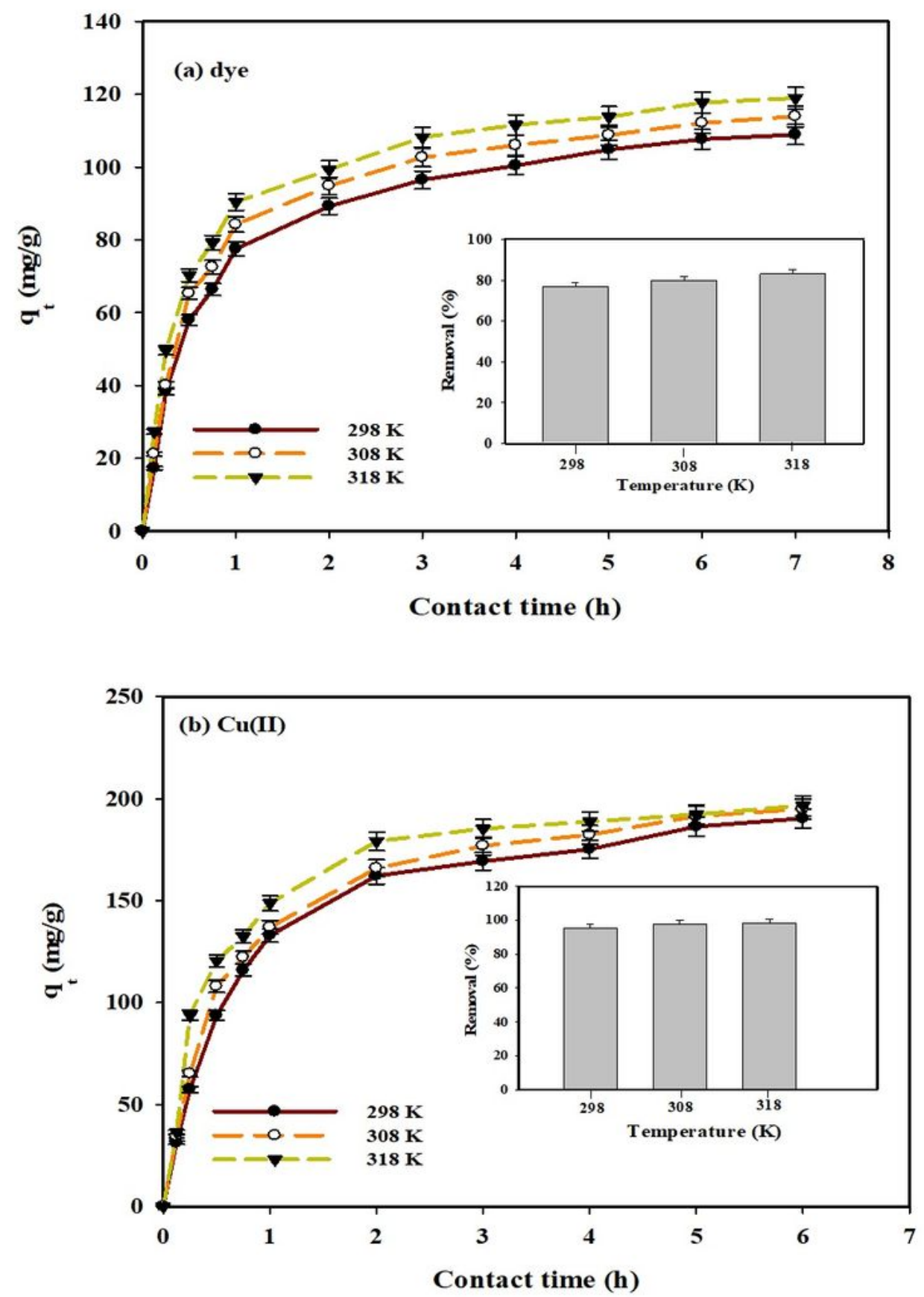

Figure 9

Impact of temperature $(\mathrm{K})$ with contact time $(\mathrm{h})$ onto the amount adsorbed $(\mathrm{mg} / \mathrm{g})$ and removal $(\%)$ of the (a) basic blue 3 dye and (b) $\mathrm{Cu}$ (II) ions onto PVA-co-AAm/TiO2/SiO2-30 nanocomposite (pH11 for the dye and $\mathrm{pH} 6$ for $\mathrm{Cu}$ (II) ions; contact time $7 \mathrm{~h}$ for the dye and $6 \mathrm{~h}$ for $\mathrm{Cu}$ (II); $0.3 \mathrm{~g}$ adsorbent dosage; initial concentration $150 \mathrm{mg} / \mathrm{L}$ for the dye and $200 \mathrm{mg} / \mathrm{L}$ for Cu (II) ions; agitation speed $100 \mathrm{rpm}$ ). 

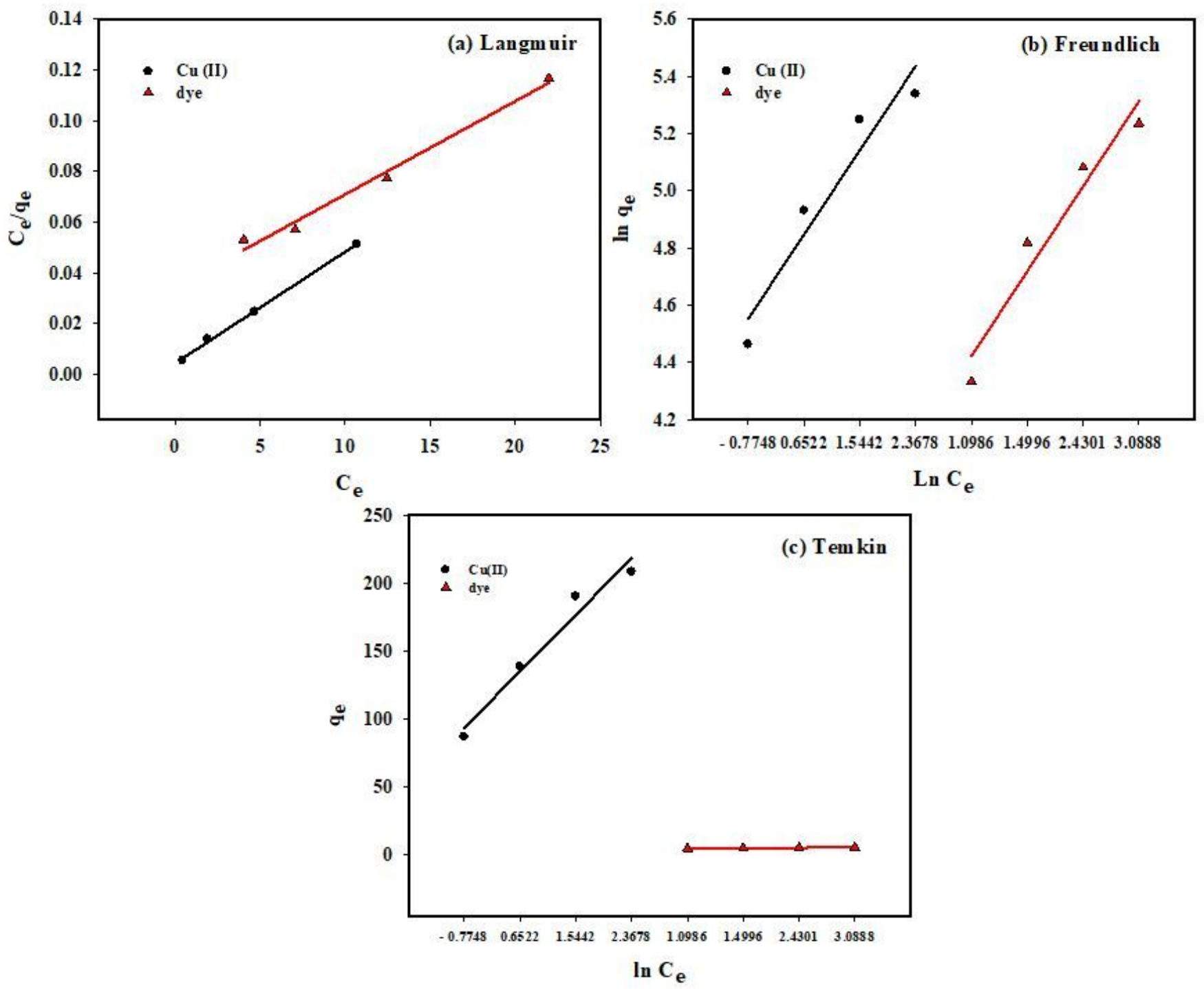

Figure 10

(a) Langmuir, (b) Freundlich and (c) Temkin isotherm for adsorption of basic blue 3 dye and Cu (II) ions onto PVA-co-AAm/TiO2/SiO2-30 nanocomposite. 

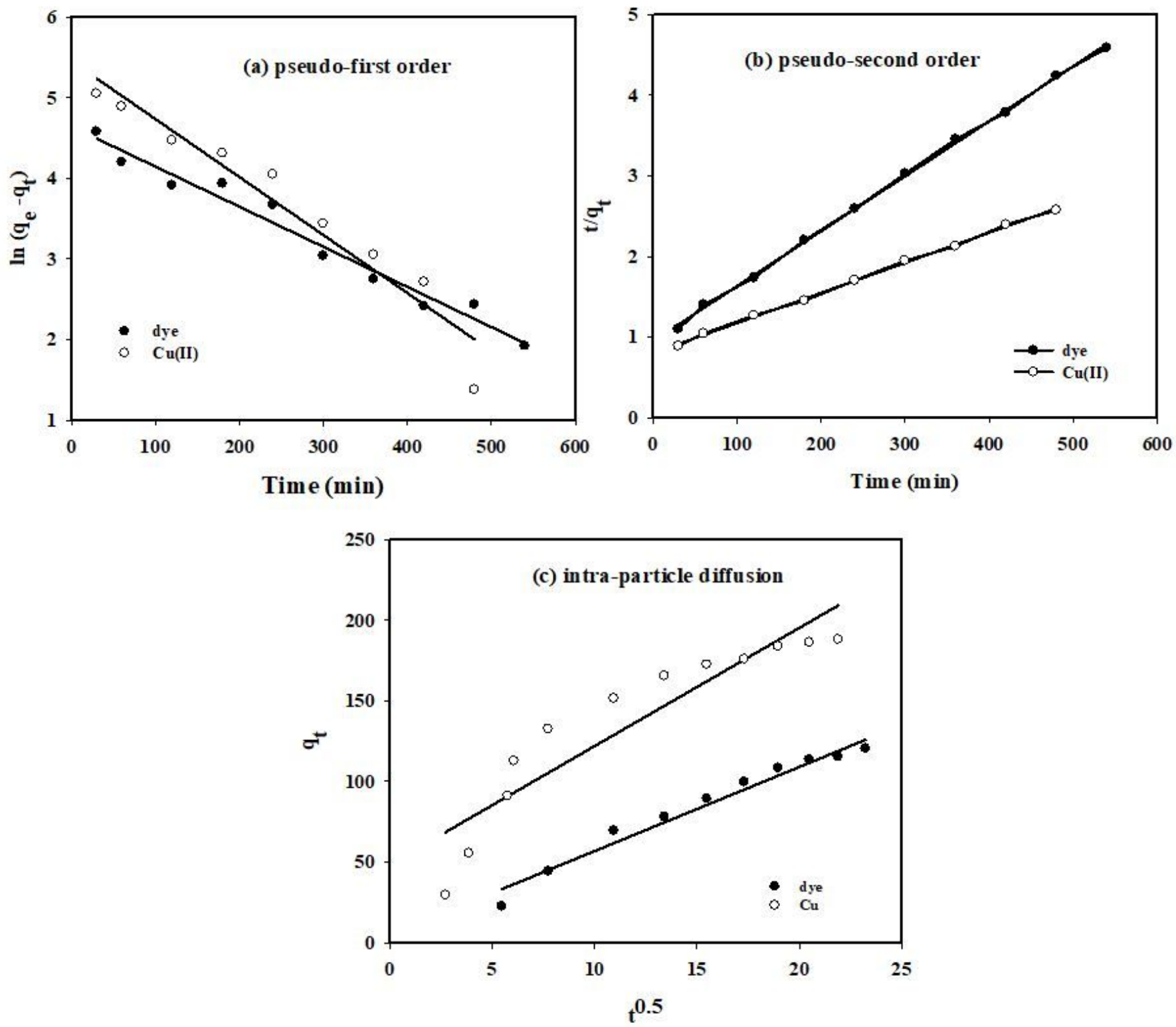

Figure 11

plots of (a) pseudo first order, (b) pseudo second order and (c) intra-particle diffusion kinetic models applied for adsorption of basic blue 3 dye and $\mathrm{Cu}(\mathrm{II})$ ions onto PVA-co-AAm/TiO2/SiO2-30 nanocomposite. 


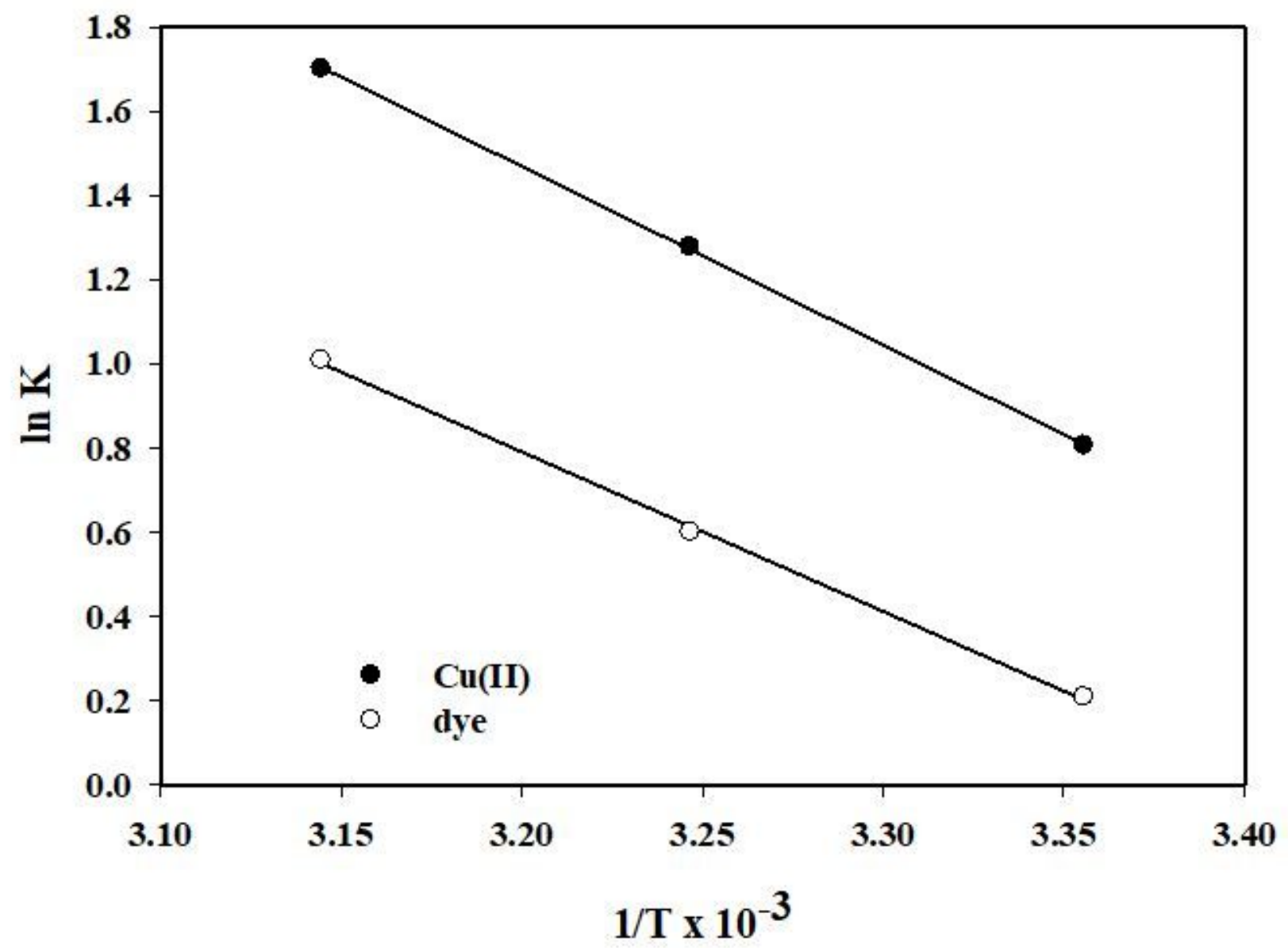

Figure 12

Van't Hoff plots of the $\mathrm{Cu}$ (II) ions and basic blue 3 dye adsorption at different temperatures ( $50 \mathrm{ml}$ of initial concentration $150 \mathrm{mg} / \mathrm{l}$ for the dye and $200 \mathrm{mg} / \mathrm{I}$ for $\mathrm{Cu}(\mathrm{II})$ ions; $0.3 \mathrm{~g}$ adsorbent dosage, $\mathrm{pH} 6$ for $\mathrm{Cu}$ (II) and pH 11 for the dye; contact time $6 \mathrm{~h}$ for $\mathrm{Cu}$ (II) and $7 \mathrm{~h}$ for the dye). 


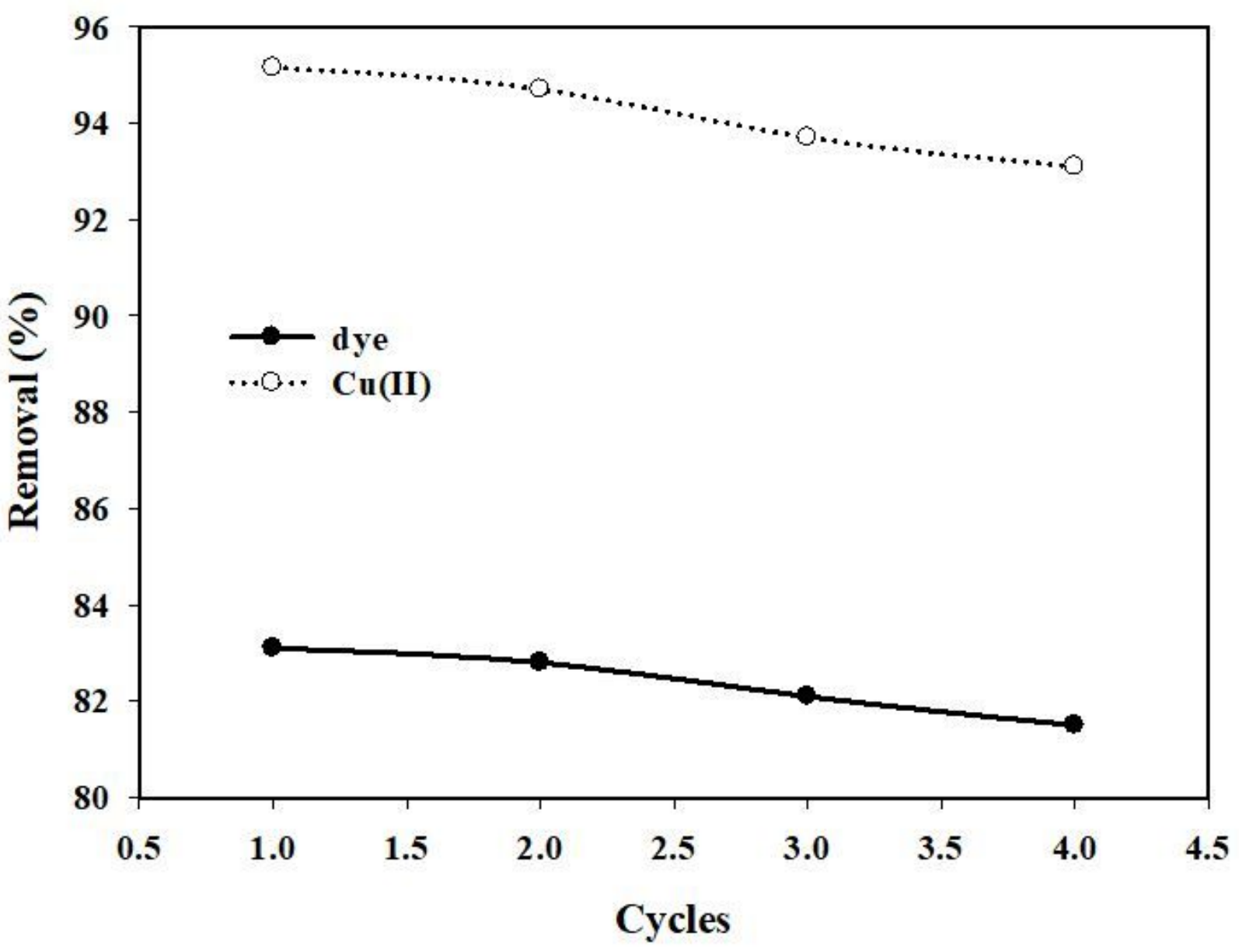

Figure 13

effect of cycle times on removal (\%) of basic blue 3 dye and $\mathrm{Cu}(\mathrm{II})$ onto PVA-co-AAm/TiO2/SiO2-30 nanocomposite 